\title{
Economic Performance Evaluation of Process System Design Flexibility Options Under Uncertainty: The Case of Hydrogen Production Plants with Integrated Membrane Technology and $\mathrm{CO}_{2}$ Capture
}

\author{
Liang-Chih Ma, Bernardo Castro-Dominguez, Nikolaos K. Kazantzis *, Yi Hua Ma \\ Center of Inorganic Membrane Studies, Department of Chemical Engineering, \\ Worcester Polytechnic Institute (WPI), Worcester, Massachusetts 01609-2280, USA
}

\begin{abstract}
A hydrogen production plant with integrated catalytic membrane reactor modules (HP-CMR) represents a new technology option with potentially enhanced environmental performance characteristics. Therefore, HP-CMR techno-economic performance in the presence of irreducible sources of uncertainty (market, regulatory) ought to be comprehensively evaluated in order to accelerate the realization of future demonstration plants. The present study introduces a systematic methodological framework allowing the economic value assessment of various flexibility options in the design and operation of an HP-CMR plant under the above uncertainty sources. The primary objective is to demonstrate the potentially value-enhancing prospects of design flexibility options that capture the inherent optionality element in managerial decisionmaking to actively respond to uncertainties as they are progressively resolved. A detailed Net Present Value (NPV)-based assessment framework is first developed within which the above sources of uncertainty are integrated through Monte Carlo techniques. Various constructional and operational flexibility options are introduced pertaining to the installation decision and operating mode choice of the carbon capture and sequestration (CCS) unit, and HP-CMR economic performance is comparatively assessed. Finally, under certain scenarios of regulatory action on $\mathrm{CO}_{2}$ emissions, it is demonstrated that quite appealing economic performance outcomes could emerge for HP-CMR plants once design flexibility is introduced.
\end{abstract}

Keywords: Catalytic membrane reactor, Hydrogen production, $\mathrm{CO}_{2}$ capture, Process system design flexibility options, Economic performance evaluation under uncertainty.

\footnotetext{
* Author to whom correspondence should be sent; Address: 100 Institute Road, Department of Chemical Engineering, Worcester Polytechnic Institute, Worcester, MA 01609-2280, USA; E-mail address: nikolas@wpi.edu; Phone number: +353-83-8849628. Part of this work was performed while N. Kazantzis was at Hughes Hall, University of Cambridge, UK.
} 


\section{Introduction - Preliminaries}

Global energy consumption growth, dependency patterns on fossil fuels as well as climate change mitigation challenges inexorably lead to an intensification of the exploration and development of energy resource alternatives. Within such a context, hydrogen $\left(\mathrm{H}_{2}\right)$ emerges as one of the most promising alternatives [1]. Midilli et al. [2] reported that the nature of the primary resource in the various technical pathways for $\mathrm{H}_{2}$ production could potentially evolve from the current ones dominated by conventional fossil fuels to renewable sources. Nonetheless, there is also an emergent awareness aiming at the deployment of coal gasification systems in $\mathrm{H}_{2}$ production mainly due to the abundance of coal reserves and the relative low average values and mild volatility associated with global coal price movement patterns [3]. Along with the development of coal gasification technologies, the regulation of $\mathrm{CO}_{2}$ emissions becomes critical in light of the nature and scale of climate change challenges. The use of coal for power generation is a major contributor to $\mathrm{CO}_{2}$ emissions [4] and consequently, due to persistent demand pressure for fossil fuels, future regulatory action on $\mathrm{CO}_{2}$ emissions in the U.S. remains a reasonable expectation.

The integration of carbon capture and sequestration (CCS) systems/units into conventional $\mathrm{H}_{2}$ production plants represents a practical and potentially useful approach to reduce $\mathrm{CO}_{2}$ emissions while being aligned with the concept of sustainable design through process integration to prevent pollution [5-8]. Due to technology innovation, the cost profiles of pre-combustion CCS technology options for power generation as well as clean $\mathrm{H}_{2}$ production have become gradually more economically appealing in the past decade $[9,10]$. Therefore, the use of membranes is recognized as a promising technology for CCS due to its technical efficiency and satisfactory economic performance characteristics [11-15]. In particular, Pd/alloy-based catalytic membrane reactors (CMRs) can perform the water-gas shift (WGS) reaction and $\mathrm{H}_{2}$ separation simultaneously, enabling the generation of pure $\mathrm{CO}_{2}$ and $\mathrm{H}_{2}$ in a single unit [9,16-20]. Furthermore, $\mathrm{H}_{2}$ yields are higher due to the so-called process intensification effect, which occurs when $\mathrm{H}_{2}$ is removed in-situ through the membrane. This continuous $\mathrm{H}_{2}$ removal allows higher $\mathrm{CO}$ conversion levels to be attained when compared to conventional reactors. The underlying operating principle of a CMR used for the co-production of pure $\mathrm{H}_{2}$ and $\mathrm{CO}_{2}$ is illustrated in Figure 1 in which a $\mathrm{Pd} /$ alloy composite membrane is positioned along the catalytic bed allowing its surface to be exposed to the $\mathrm{H}_{2}$ generated by the reaction. All these features of CMRs integrated into coal-fired $\mathrm{H}_{2}$ production (HP-CMR) plants (Figure 2) could potentially contribute to the emergence of enhanced 
economic performance profiles in the presence of regulatory actions on carbon as demonstrated in our previous study [9]. However, potentially value-enhancing flexibility options in the design and operation of an HP-CMR plant have not been considered for the enhancement of economic performance profiles. As shown in Figure 2, the CCS system (in red) is an optional unit that could be integrated into an HP-CMR plant through plant retrofitting/restructuring. With the aid of potentially value-enhancing flexibility options the plant retrofit/restructure and also the CCS operating moderelevant decision points could be governed by specific managerial decision rules in response to uncertain carbon tax scenarios, and the trade-off between carbon tax-relevant (regulatory) costs and costs associated with the CCS unit installation/operation could be optimized. A more detailed description about design flexibility options for an HP-CMR plant under uncertain carbon tax scenarios is provided in Section 2.2. The primary focus of the present study is the development of a preliminary, yet methodologically sound, assessment of potentially value-enhancing flexible design options for HPCMR plants in order to inform policy initiatives for the realization of an initial fleet of technology demonstration plants (for technical feasibility, economic viability demonstration and risk characterization purposes). Furthermore, investment decisions in new technology options are fraught with risks and uncertainties which may be associated with economy-wide factors that affect the demand and price for $\mathrm{H}_{2}$, as well as the availability of labor and capital, developments in fuel and commodity markets, factors pertaining to the evolution of the regulatory landscape, technological risks and also financial risks related to the structure of the underlying financing mechanism. Therefore, any preliminary attempt to assess the economic viability of HP-CMR as well as its performance-enhancing prospects through various design flexibility options while methodologically acknowledging irreducible (i.e. regulatory, market, technological) uncertainties is certainly justified. 


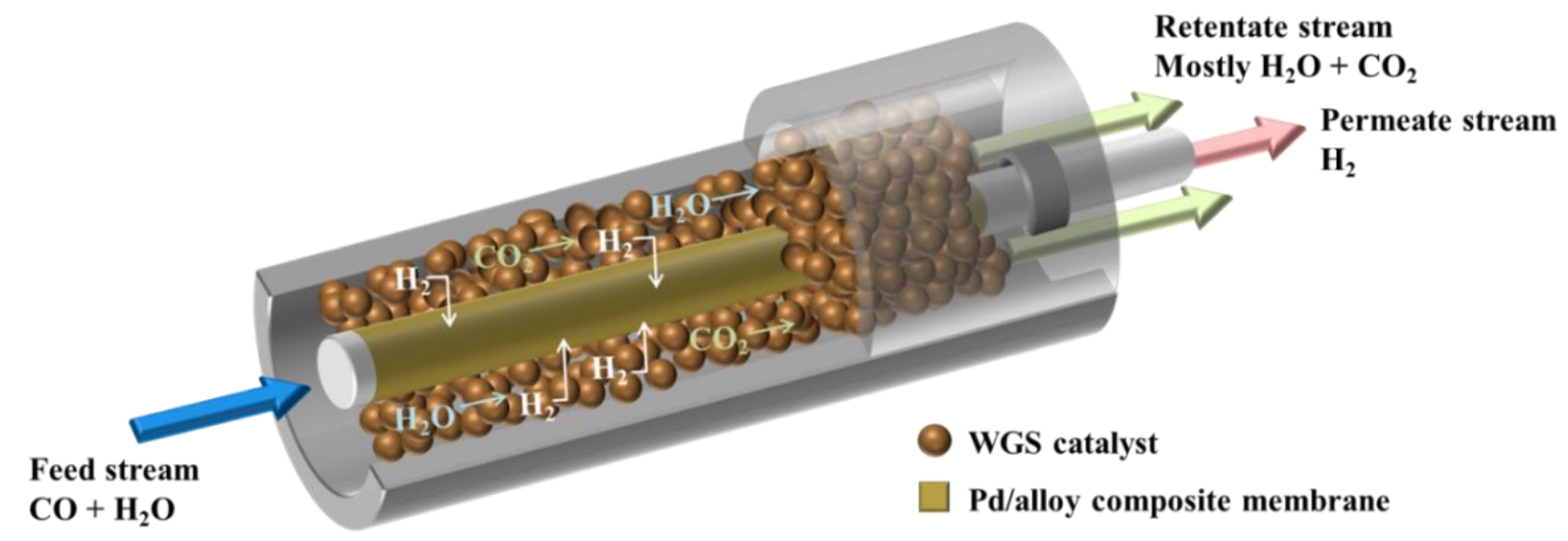

Figure 1. Schematic diagram of the Pd/alloy-based CMR used for co-production of pure $\mathrm{H}_{2}$ and highly pressurized clean $\mathrm{CO}_{2}$.

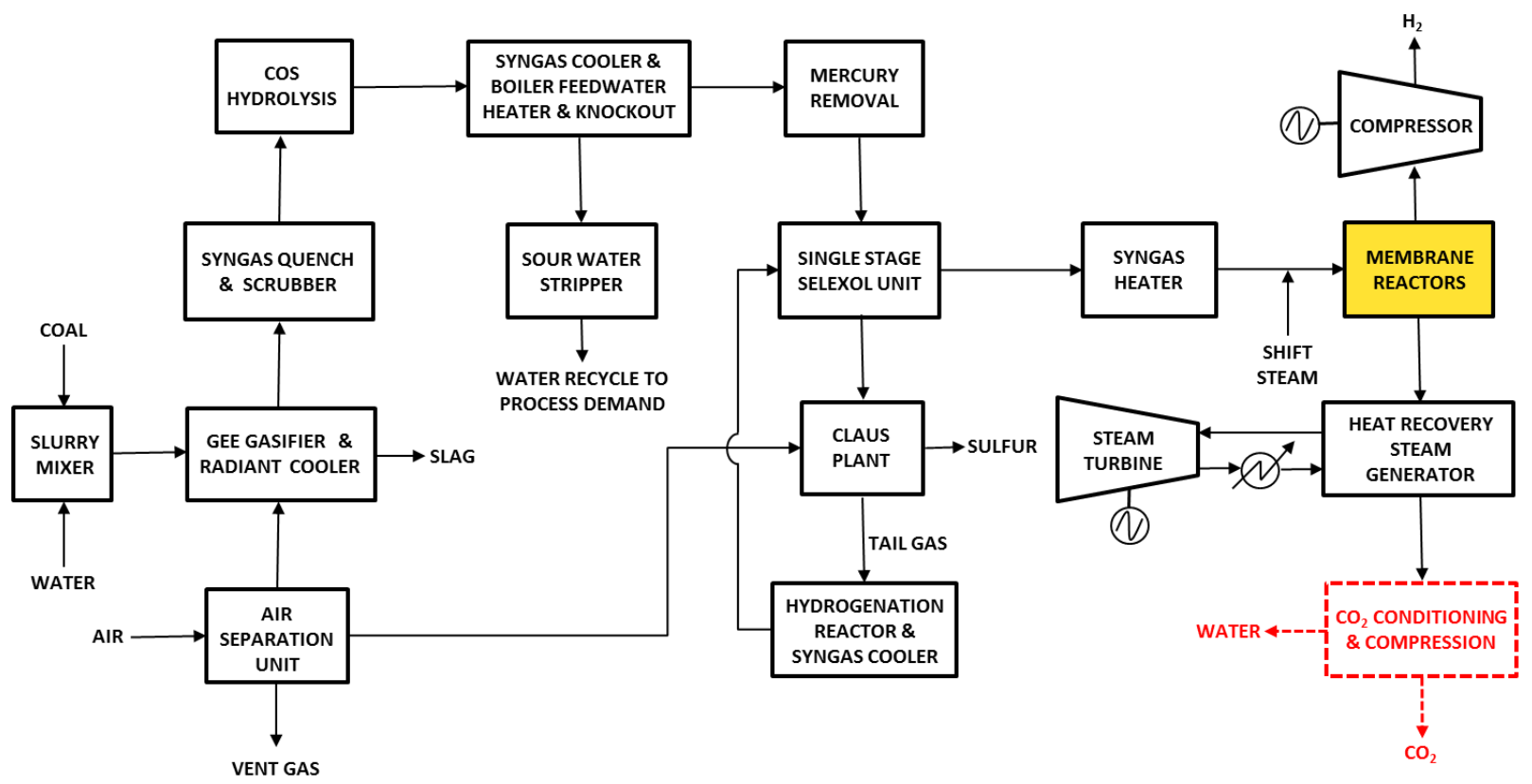

Figure 2. Process block flow diagram of the coal-fired HP-CMR plant without and with $\mathrm{CO}_{2}$ capture (in red).

While previous work focused on the development of a systematic economic performance assessment framework for coal-fired HP-CMR plants in the presence of various sources of uncertainty [9], potentially value-enhancing flexibility options in the design and operation of an HP-CMR plant 
have not been considered. In particular, the primary objective of this study is to demonstrate the potentially value-enhancing prospects associated with flexibility options for HP-CMR plants that capture the inherent optionality element in managerial decision-making to respond to the above market and regulatory uncertainties as they are progressively resolved. Therefore, various constructional and operational flexibility options could be envisioned pertaining to the installation decision and the operating mode choice respectively of a CCS unit in a HP-CMR plant. For example, the plant management team may recognize the need and also (the potentially valuable) option to immediately proceed with, or delay or finally abandon the installation project of a CCS system or even switch its operating mode (enabled by flexible design) depending on how conditions in the regulatory environment evolve in order to enhance overall economic performance of the plant over its lifetime. This way, the element of optionality inherent in managerial decision-making that is enabled by design flexibility is explicitly acknowledged in the proposed economic performance evaluation framework under uncertainty. Such a framework and valuation context will inform efforts by process systems engineers and managers to characterize and eventually enhance the HP-CMR plant's adaptability. In the present study, it is shown that explicitly recognizing flexibility can help improve the economic value of a promising clean technology option such as HP-CMR.

The importance of considering engineering design flexibility options is based on the inability to forecast accurately the long-term benefits and costs of technology systems. Furthermore, the objective of process systems engineering design has been traditionally to create robust prototypes that can perform satisfactorily under unexpected circumstances. Nonetheless, designers quite often do not explicitly acknowledge and incorporate uncertainties over time into their frameworks, and thus, conventional design prototypes are often based on unrealistically narrow ranges of conditions. Consequently, de Neufville et al. [21] (i) recognized the limitations in traditional design and project valuation approaches in dealing with irreducible uncertainties, and (ii) underlined that process design, rather than aiming at "passively" meeting certain performance criteria, should explicitly and actively consider uncertainties as a core element thus allowing the derivation of distribution profiles of possible economic performance outcomes (rather than potentially misleading single-point estimates) where both risks and opportunities can be identified and characterized. The concept of flexible design was used and integrated into the aforementioned valuation framework that explicitly recognizes the right (but not the obligation) to change the system's design and/or operating mode in response to uncertainties 
that progressively unfold [22], and as a result to enhance economic performance over the plant's/project's lifetime. In two pieces of seminal research work, de Neufville and Scholtes [23] and Cardin [24] later provided an overview of the pertinent concepts and attendant procedures as they apply to the design of complex engineering/process systems. Conceptually aligned with this work, design and operational flexibility endows engineering/process systems with the ability to adapt, change, and be reconfigured when facing uncertainties [23,25]. Design flexibility can also potentially alleviate negative impacts from downside risks (acting as an insurance policy) and/or enhance benefits associated with upside opportunities in an uncertain world by embracing a dynamic pro-active framework to analyze, respond and manage the effect of various sources of irreducible uncertainty on the system's lifetime techno-economic performance [23,24,26]. Within this context, Al-Mutairi and ElHalwagi [27] developed a rigorous and insightful approach for a class of process systems focusing on facility retrofitting, process scheduling, and system operation in order to maximize profits generated in response to uncertainty that underlies market demands and environmental regulations. Additionally, Zhang et al. [28] evaluated potentially value-enhancing flexibility options for Integrated Gasification Combined Cycle (IGCC) power plants with embedded membrane reactor modules (IGCC-MR) under various uncertain $\mathrm{CO}_{2}$ emissions tax scenarios.

The inadequacy of traditional valuation methodologies applied to advanced engineering systems/projects and technology options under uncertainty provides further motivation for the study of engineering design flexibility. Indeed, traditional valuation methods of engineering projects based on discounted future cash flow (DCF)-model and the associated NPV-metric do not offer an explicit way to incorporate and quantify uncertain conditions that could have asymmetric impacts on economic performance outcomes, i.e. evaluating economic performance at average conditions does not necessarily represent average economic performance (known as the "flaw of averages" in probability theory [23]). These limitations can be effectively overcome by the integration of Monte Carlo simulation techniques as demonstrated in $[9,20,23,25,29]$.

Flexibility in engineering design can be classified into two categories: flexibility "on" engineering systems and flexibility "in" engineering systems [23,24,28]. Typically, flexibility options “on" engineering systems are recognized as operational flexibility where managerial decision rules are based on the system operation and management. Unlike flexibility options "on" engineering systems, 
flexibility options "in" engineering systems are referred to as constructional flexibility which focuses on the modularity embedded in the process system design.

Operational flexibility can take various forms, primarily including fuel, product and volume flexibility [26]. Fuel flexibility indicates the capacity to change the primary composition of the fuel mix used in the production line in response to uncertainties in the pertinent fuel markets. For example in coal-fired $\mathrm{H}_{2}$ production plants, the gasifier could accommodate a variety of primary fuels, including coal, petroleum coke, biomass to produce syngas for $\mathrm{H}_{2}$ production. The selection of the primary fuels is determined by decision rules in order to prevent or minimize the potentially negative impact of fuel market volatility on the plant's economic performance profile over its lifetime but also capitalize potentially favorable developments in the pertinent fuel markets. Product flexibility is conceptualized as the ability to manufacture different products with the same production line. This kind of operational flexibility is introduced to cope with market and demand-relevant uncertainty impacting product sales. Volume flexibility represents the capability to change total product volumes in response to uncertain economic, market and regulatory environments. From a different view point, volume flexibility is also recognized as the capacity to adjust the system's operational or production modes such as expanding/contracting/freezing production capacity or even shutting down the CCS-unit or the plant operation itself under (favorably/adversely) evolving macroeconomic and/or regulatory conditions.

Constructional flexibility focuses on options to retrofit and structurally change the original design of the plant such as adding or removing components/process units [26]. Two sources of concern may be identified in constructional flexibility studies; one is associated with the timing of the restructuring/retrofitting activities for the system under consideration, while the other one is associated with the initial system design that potentially allows the physical realization of the aforementioned modularity [26,28]. Both concerns are of course associated with specific capital investment requirements and system performance after restructure/retrofit. Finally, constructional flexibility options could be in principle combined with operational flexibility ones so that the resulting system performance could potentially benefit through the combination of these two different types of engineering design flexibility methodologies at the expense of adding complexity to the task of exercising these options [28]. 
In light of the above considerations, the objective of the present research study is to introduce viable design flexibility options for coal-fired HP-CMR plants and evaluate their potentially valueenhancing capabilities through the proposed methodological and analytical economic performance assessment framework. The paper is organized as follows: Section 2 provides the foundations and structural characteristics of the proposed economic assessment framework that allows the identification and incorporation of potentially value-enhancing design flexibility options in the presence of uncertainty. Section 3 encompasses the paper's main results and a detailed discussion of its key findings. Finally, a few concluding remarks are provided in Section 4.

\section{Methodological Framework}

\subsection{Baseline Net Present Value-model development}

A sound measure of the increase/decrease in wealth induced by an investment in an engineering project is the net present value (NPV) as introduced in standard finance and investment valuation theory [30]. Furthermore, NPV is a risk neutral valuation metric used to assess economic performance over the engineering project's lifetime and a very reliable one for ranking valuation outcomes of various engineering design options as well as competing technology platforms [30]. As delineated in the sequel, the proposed economic performance assessment framework can readily accommodate complementary economic performance metrics such as the "value at risk" and "value at opportunity" that are aligned with the perspective of a "risk-averse" and "opportunity-seeker" decision maker respectively. Consequently, the additional information generated within the proposed methodological framework allows the management team to gain enhanced insight into the HP-CMR plant's economic performance profile in an uncertain world.

First the development of a baseline functional NPV-model is pursued in order to form a benchmark case against which all flexible design options considered in the present study are comparatively assessed. Please notice that a set of detailed cost and revenue "value-drivers" for this economic model (model input variables) needs to be identified. Within a traditional deterministic framework, these inherently uncertain quantities are considered fixed at "average/expected" values, and the analysis is conducted for all possible design alternatives/options. In particular, in the baseline 
model NPV is calculated by subtracting the initial Total Capital Investment (TCI) from the sum of discounted cash flows throughout the plant's lifetime [30], as shown in Equation 2-1:

$$
\mathrm{NPV}=\sum_{\mathrm{t}=1}^{\mathrm{n}} \frac{\mathrm{CF}_{\mathrm{t}}}{(1+\mathrm{r})^{\mathrm{t}}}-\mathrm{TCI}
$$

where $\mathrm{CF}_{\mathrm{t}}$ denotes the nominal net cash flow in year $t$, which is comprised of the Total Product Cost (TPC), depreciation, the plant's salvage value and the hydrogen selling revenue; $n$ indicates the plant's lifetime, and $r$ is the plant's nominal discount rate determined by perceived project/technology risks as well as the project's underlying financing mechanism [30]. Please notice that the above baseline NPVmodeling framework relies on the following fundamental principles and assumptions:

1. For all the cases shown in this work, the HP-CMR plant is fueled by coal and assumed to produce 685 tonnes $\mathrm{H}_{2}$ per day having a lifetime of 30 years in agreement with the assumptions accompanying the hydrogen production plant description presented in the pertinent DOE/NETL report [7].

2. Following standard procedures/practices in engineering systems economic performance analysis and appraisal, the initial TCI was estimated as the sum of Working Capital (WC) and Fixed Capital Investment (FCI) encompassing both direct and indirect costs [31,32]. In particular, for the integration of the Pd/alloy-based CMR module into the above hydrogen production plant, cost components associated with direct costs involve purchased equipment (including WGS reactors, HTS catalysts, and Pd/Au alloy composite membrane tubes), installation, installed instrumentation and controls, installed piping, installed electrical units, buildings, process and auxiliary units, service facilities and yard improvements, as well as land. Indirect costs include engineering and supervision pertinent costs, legal expenses, construction expense and contractor's fees, as well as contingency-relevant costs (for a more detailed description please see $[9,29,31,32])$.

3. The CMR module contains 10 bundles of CMRs in a parallel configuration with $4313 \mathrm{Pd} / \mathrm{Au}$ alloy (12 wt $\% \mathrm{Au})$ composite membrane tubes, operated at $400^{\circ} \mathrm{C}$ and 50 bar to achieve the 
desired $\mathrm{H}_{2}$ production target [9]. Furthermore, a $\mathrm{CO}_{2}$ compression of 150 bar with intercooling/dehydration was used before its sequestration [7].

4. Cost figures of assorted process units and equipment are adopted from the DOE/NETL report [33], and are recalculated with the aid of the six-tenths factor rule (an empirical correlation that relates cost to size of a manufacturing facility) to satisfy the commercial HP-CMR plant's operational and production requirements due to a lack of pertinent cost data available in the literature $[9,31]$.

5. The Chemical Engineering Plant Cost Indexes (available for year 2014 [34]) are used to update all pertinent cost estimates, without considering any cost-reducing possibilities due to future technological advances and "learning-effects."

6. The estimation of TPC is calculated by forming the sum of production cost (PC) and general expenses (GE) in accordance with standard procedures in engineering systems economic analysis, as shown in Equation 2-2, 2-3 and 2-4 [31]. The production cost is comprised of several cost components involving operating costs (OC) (as the sum of fuel, fixed and variable operation and maintenance $(\mathrm{O} \& \mathrm{M})$ costs, as well as membrane replacement costs), $\mathrm{CO}_{2}$ transport and storage costs (CTSC), $\mathrm{H}_{2}$ delivery cost (HDC), carbon tax (CT), insurance (INS), patents and royalties (PR), as well as plant overhead costs (POC). General expenses include administrative costs (AC), marketing costs (MC), research and development (R\&D) costs (RDC) as well as financing interest costs (FIC) (for a more detailed description please see $[7,9])$.

$\mathrm{TPC}=\mathrm{PC}+\mathrm{GE}$

$\mathrm{PC}=\mathrm{OC}+\mathrm{CTSC}+\mathrm{HDC}+\mathrm{CT}+\mathrm{INS}+\mathrm{PR}+\mathrm{POC}$

$\mathrm{GE}=\mathrm{AC}+\mathrm{MC}+\mathrm{RDC}+\mathrm{FIC}$

7. Hydrogen sales is the only revenue stream generated from operating the coal-fired HP-CMR plant and it is calculated as follows:

$$
\mathrm{R}_{\mathrm{t}}=\mathrm{SP}_{\mathrm{t}} \cdot \mathrm{CPF}_{\mathrm{t}} \cdot \mathrm{PS} \cdot\left(1-\mathrm{DF}_{\mathrm{t}}\right) \cdot 1000 \cdot 365
$$

where $\mathrm{R}_{\mathrm{t}}$ is the annual revenue generated by $\mathrm{H}_{2}$ sales at year $\mathrm{t}$; $\mathrm{SP}_{\mathrm{t}}$ is the selling price of hydrogen in units of US\$/kg at year $\mathrm{t} ; \mathrm{CPF}_{\mathrm{t}}$ is the capacity factor at year $\mathrm{t}$; PS is the plant 
production capacity of 685 tonnes $\mathrm{H}_{2}$ per day; $\mathrm{DF}_{\mathrm{t}}$ is the de-rating factor associated only with certain constructional flexibility options as discussed in the pertinent literature [28]. It is important to mention that the value of CPF might change when the CCS system is operated $[20,28]$ (and net efficiency, plant energy requirements and output de-rating are correlated). For instance, it is easy to imagine a higher electric consumption when the CCS system is integrated. Certainly, cooling/heating requirements also increase (in parallel to electricity) and therefore, in order to compensate for this situation, the energy requirements for the generation of hydrogen are reduced (total energy requirement for the plant is considered fixed in this work) affecting $\mathrm{H}_{2}$ production output. It is also possible to observe that when the HP-CMR plant is retrofitted with a CCS system various plant components/units need to be adjusted so that the integration of the CCS system into the plant can be accommodated. The above unit/equipment adjustments/resizing may lead to new operating conditions and design requirements, thereby affecting the hydrogen production rate as well. Finally, in the absence of any accumulated operating experience at the demonstration level, a lower capacity factor for this new untested technology option is also justified when viewed as a conservative means to quantitatively capture higher inherent technology risks particularly in the presence of an operating CCS (and thus the likelihood of increased frequency of plant shutdowns, stringent maintenance scheduling, etc.).

8. The inflation rate $(\alpha)$ used in the calculation of the discounted cash flows is estimated as follows:

$$
\alpha_{\mathrm{t}}=\frac{\mathrm{CPI}_{\mathrm{t}}}{\mathrm{CPI}_{\mathrm{t}-1}}-1
$$

where $\alpha_{t}$ is the inflation rate at year $t$ and CPI is the consumer price index reported by the U.S. Department of Labor (U.S.DOL) [35].

9. Depreciation-relevant expenses are recognized as an allocated portion of the cost of assets over accounting periods in which assets are used. In practice, it acts as a tax shield $(\psi)$ and is calculated as follows [9,30]:

$$
\psi_{\mathrm{t}}=\mathrm{DR}_{\mathrm{t}} \cdot \mathrm{FCI} \cdot\left(\theta_{\text {Federal }}+\theta_{\text {State }}\right)
$$


where $\psi_{\mathrm{t}}$ denotes the tax shield generated by depreciation in year $t ; \mathrm{DR}_{\mathrm{t}}$ represents the depreciation rate in year $t$ in compliance with reporting conventions used by the Internal Revenue Service (IRS), U.S. Department of Treasury [36], and $\theta_{\text {Federal }}$ and $\theta_{\text {State }}$ are the federal corporate tax rate and the combined state and local sales tax rate respectively. Please note that the value of $\theta_{\text {Federal }}$ conforms to the federal corporate tax schedule enacted by the IRS, U.S. Department of the Treasury [37], while the value of $\theta_{\text {State }}$ depends on plant location and pertinent state government policies [38].

10. The salvage value (SV) is the resale value of the HP-CMR plant at the end of its lifetime. The value of SV can be estimated through Equation 2-8 [30]:

$$
\mathrm{SV}=\mathrm{MV}-(\mathrm{MV}-\mathrm{BV}) \cdot\left(\theta_{\text {Federal }}+\theta_{\text {State }}\right)
$$

where MV represents the market value of the HP-CMR plant and BV denotes its book value. The term (MV-BV) is used to indicate the taxable gain when the plant is sold. Due to the recovery period of 20 years considered in this study, BV becomes zero after 20 years.

11. As mentioned earlier, $\mathrm{CF}_{\mathrm{t}}$ consists of the hydrogen selling revenue, total product cost, depreciation, as well as the plant's salvage value. In particular, $\mathrm{CF}_{\mathrm{t}}$ can be calculated as follows:

$$
\begin{array}{lll}
\mathrm{CF}_{\mathrm{t}}=\left(\mathrm{R}_{\mathrm{t}}-\mathrm{TPC}_{\mathrm{t}}\right) \cdot\left(1-\theta_{\text {Federal }}-\theta_{\text {State }}\right)+\psi_{\mathrm{t}} & \text { where } \mathrm{t}=1,2, \ldots, 29 & 2-9 \\
\mathrm{CF}_{\mathrm{t}}=\left(\mathrm{R}_{\mathrm{t}}-\mathrm{TPC}_{\mathrm{t}}\right) \cdot\left(1-\theta_{\text {Federal }}-\theta_{\text {State }}\right)+\psi_{\mathrm{t}}+\mathrm{SV} & \text { where } \mathrm{t}=30 & 2-10
\end{array}
$$

where $\mathrm{TPC}_{\mathrm{t}}$ indicates the annual total product cost at year $\mathrm{t}$.

12. The HP-CMR plant is assumed to be built in 2014 and start operating in 2015 (we used the latest Chemical Engineering Plant Cost Index as well as pertinent data from the US Department of Labor, US Department of Treasure and the Tax Foundation available [34-38]), while the $\mathrm{CO}_{2}$ tax is assumed to be introduced in 2017. In this study, a standard stochastic Geometric Brownian Motion model $[39,40]$ is adopted in order to probabilistically represent and simulate throughout the plant's lifetime the uncertain $\mathrm{CO}_{2}$ emissions tax rate (\$/tonne) parametrized by the initial $\mathrm{CO}_{2}$ tax rate, the drift term $\mu$ representing the expected annual growth rate of the $\mathrm{CO}_{2}$ 
tax and the volatility term $\sigma$ corresponding to the volatility of the $\mathrm{CO}_{2}$ tax rate along the aforementioned regulatory policy path.

13. Given that outstanding technical performance levels can be achieved by CMR technology (99\% $\mathrm{CO}$ conversion and $96 \% \mathrm{H}_{2}$ recovery $[9,19,20]$ ), the HP-CMR plant can subsequently display a very high $\mathrm{CO}_{2}$ separation capacity; nonetheless, a rather conservative $98 \% \mathrm{CO}_{2}$ capture efficiency is assumed in order to prevent any overestimation of the associated economic performance $[9,19,20]$.

Please notice that the development of the baseline functional NPV-model, following standard financial theory [30], was structurally informed and conceptually based on previous research studies $[9,20]$ in which the NPV-model was used to evaluate and characterize the economic performance profiles of an HP-CMR and an IGCC-MR system respectively in the presence of irreducible uncertainty. Therefore, within the context of the present study, the use of the proposed NPV-model is well justified for an assessment of potentially value-enhancing flexibility options in response to uncertainty.

\subsection{Design Flexibility Options}

The present study focuses on identifying various design flexibility options (Table 1) that could potentially enhance the lifetime valuation profile of an HP-CMR plant through actively managing the irreducible uncertainty associated with a reasonably anticipated future regulatory action on $\mathrm{CO}_{2}$ emissions. As mentioned earlier, among the various forms of operational flexibility, volume flexibility could be considered for an HP-CMR plant. Indeed, volume flexibility is envisioned as the capacity to adjust the system's operational or production modes such as expanding/contracting/freezing production capacity or shutting down the CCS-system's or the plant's operation itself in response to evolving favorable/unfavorable economic and/or regulatory conditions. Based on this concept, a flexibility option is considered to shut down the plant for a year if the cash flows for the previous two consecutive years are negative. Plant operation could resume when the estimated cash flows, which now incorporate an extra O\&M cost for plant start-up, are positive in the previous two consecutive years. Case B is used to represent an HP-CMR plant for which this kind of flexibility option could be exercised by the management team. Please notice that this flexibility option is introduced in the fifth 
year of plant operations (i.e. in the third year after the introduction of the $\mathrm{CO}_{2}$ tax). It should be also pointed out that the proposed operational flexibility decision rules are parameterized by the choice of the "size/duration" of the time intervals before a decision is made to possibly change the plant's operating mode. In the context of our study, our choice, i.e. a 2-year duration or "time-length" was informed by the realization that it represents a compromise between an option advocating faster operating mode-switching (let's say annually) that could hinge on higher costs (please see [28] for a discussion on challenges pertaining to swift changes in the operating mode of plants or complex engineering systems) and an option advocating a slower switching mode (with a wider time-window) associated with the possibility of increasing risks and accumulated losses if uncertain conditions unfold in an adverse manner.

Regarding constructional flexibility, two types are considered in this study based on various design phases and the timing of installation of a CCS system. The first one is built upon the inclusion of a CCS system in the initial design phase, while the other one focuses on the installation of a CCS system at a later stage. It should be pointed out that the overall capacity of the HP-CMR plant is reduced and its economic performance profile changes when a CCS system is installed, since an output de-rating and efficiency loss inevitably occur due to the new operating conditions and requirements, and the fact that an additional cost for running the CCS system is incurred [28].

In particular, associated with the first type of constructional flexibility two options are identified and introduced as Case $\mathrm{C}$ and Case $\mathrm{D}$ respectively. Case $\mathrm{C}$ represents a plant where the installation of the CCS system takes place in the initial design phase and its operation remains continuous throughout the plant's lifetime ("inflexible case"). Case D however, considers a plant where the CCS system is installed in the initial design phase, but remains operational for a year only when the cash flows generated while operating the CCS system are higher than the ones without operating the CCS system in the previous two consecutive years. In other words, according to the above criterion, the management team exercises the flexibility option only when the regulatory cost savings are higher than the cost of operating the CCS-system during the specific time window. The flexibility option considered in Case D is introduced after 2 years following the introduction of the $\mathrm{CO}_{2}$ tax. For HP-CMR plant retrofitting with a CCS system at a later stage, the following assumptions are made: 
- The CCS system considered for the HP-CMR plant incorporates the $\mathrm{CO}_{2}$ conditioning and compression units. The FCI for the CCS system in 2014 is \$39M, which is estimated based on the pertinent DOE/NETL report [7] with the aid of the six-tenths factor rule and also updated via the Chemical Engineering Plant Cost Indexes [34]. It is important to mention that the FCI for the CCS system is assumed to change with inflation rates after 2014 by taking into account the effect of purchasing power.

- The configuration of the plant has to be modified for plant retrofitting inducing an output reduction in hydrogen production due to potentially mismatched plant components according to the above modification (and the new operating conditions and design requirements as mentioned earlier).

- Retrofitting investment cost includes the retrofitting fee and the output de-rating cost [28]. The retrofitting fee is based on the FCI of the $\mathrm{CO}_{2}$ conditioning and compression unit, while the output de-rating cost is estimated by considering the building cost of a makeup plant for compensation of the output de-rating. The output reduction-relevant cost is equal to the product of the de-rating factor and the FCI of the HP-CMR plant with $\mathrm{CO}_{2}$ capture.

Under the above assumptions, two additional flexibility options are considered in the present study (Case E and Case F), by taking into account also the respective capital investment requirements as well as de-rating factors produced by plant retrofitting. In Case E, a "hybrid" flexibility option is introduced in the third year after the $\mathrm{CO}_{2}$ tax is imposed, by which the plant is retrofitted with a CCS system only when the estimated cash flows for the plant with CCS are higher than without the CCS in the previous two consecutive years. After retrofit, the same operational flexibility option regarding the CCS system operation used in Case D is also included in Case E (the time of its introduction is at the third year due to the plant retrofitting). Similarly, Case F considers a hybridization of constructional and operational flexibility options, based on exactly the same decision rules used in Case E. Nevertheless, Case F additionally takes into account a pre-investment option for constructional flexibility embedded in the original plant design (a "CCS-ready option"), which facilitates both technically and economically the plant retrofit at a later stage with a CCS system should the regulatory conditions confer advantages to exercising such an option. The pre-investment cost is equal to the output reduction-relevant cost that is calculated as the product of the de-rating factor and the FCI of the HP-CMR plant with $\mathrm{CO}_{2}$ capture as mentioned earlier. It should be pointed out that Case $\mathrm{F}$ has a lower 
value of de-rating factor than Case $\mathrm{E}$, thus reducing the cost of retrofitting and hydrogen production losses. However, TCI and the relevant cost components in TPC before retrofitting are higher in Case F. Table 1 summarizes the specific criteria or "decision rules" considered in order to exercise the above design flexibility options as identified in the present study.

Table 1. Brief description of various engineering design flexibility options.*

\begin{tabular}{|c|c|c|}
\hline Notation & $\begin{array}{l}\text { Engineering design flexibility } \\
\text { option }\end{array}$ & Description \\
\hline Case A & $\begin{array}{l}\text { No design flexibility } \\
\text { (Plant without CCS system } \\
\text { capability) }\end{array}$ & $\begin{array}{l}\text { - The HP-CMR plant does not display any } \\
\text { design flexibility (the baseline case in the } \\
\text { present study). }\end{array}$ \\
\hline Case B & $\begin{array}{l}\text { Operational flexibility (plant) } \\
\text { (Plant without CCS system } \\
\text { capability) }\end{array}$ & $\begin{array}{l}\text { - The HP-CMR plant is endowed with } \\
\text { operational flexibility. } \\
\text { Decision Rule: } \\
\text { - The plant is shut down for a year if the } \\
\text { cash flows for the previous two } \\
\text { consecutive years are negative. } \\
\text { - } \text { The plant is kept operating for a year if } \\
\text { the estimated cash flows (encompassing } \\
\text { an extra O\&M cost for start-up if needed) } \\
\text { are positive in the previous two } \\
\text { consecutive years. } \\
\text { The operational flexibility option is } \\
\text { introduced in the third year after the } \\
\text { introduction of the } \mathrm{CO}_{2} \text { tax. }\end{array}$ \\
\hline Case $\mathrm{C}$ & $\begin{array}{l}\text { No design flexibility } \\
\text { (Plant with CCS system } \\
\text { capability) }\end{array}$ & $\begin{array}{l}\text { - The HP-CMR plant includes a CCS system } \\
\text { integrated into the initial design phase. The } \\
\text { CCS system is kept operating throughout the } \\
\text { plant's lifetime. }\end{array}$ \\
\hline Case D & $\begin{array}{l}\text { Operational flexibility } \\
\text { (Plant with CCS system } \\
\text { capability) }\end{array}$ & $\begin{array}{l}\text { - The HP-CMR plant includes a CCS system } \\
\text { integrated in the initial design phase. } \\
\text { Decision Rule: } \\
-\quad \text { The CCS system is kept operating for a } \\
\text { year when the cash flows for the plant } \\
\text { with an operating CCS system are higher } \\
\text { than without one in the previous two } \\
\text { consecutive years. }\end{array}$ \\
\hline
\end{tabular}


- The operational flexibility option is introduced after 2 years following the introduction of the $\mathrm{CO}_{2}$ tax.

\begin{tabular}{|c|c|c|}
\hline Case E & $\begin{array}{l}\text { Constructional flexibility and } \\
\text { operational flexibility without any } \\
\text { pre-investment for future plant } \\
\text { retrofit } \\
\text { (Plant with CCS system } \\
\text { capability) }\end{array}$ & $\begin{array}{l}\text { - The HP-CMR plant considers constructional } \\
\text { and operational flexibility options without } \\
\text { any pre-investment for future plant } \\
\text { retrofitting purposes. } \\
\text { - The constructional flexibility option } \\
\text { considered is introduced in the third year after } \\
\text { the introduction of the } \mathrm{CO}_{2} \text { tax. } \\
\text { Decision Rule: } \\
\text { - The plant is retrofitted with a CCS } \\
\text { system when the estimated cash flows for } \\
\text { the plant with an operating CCS system } \\
\text { are higher than without one in the } \\
\text { previous two consecutive years. } \\
\text { The operational flexibility option is } \\
\text { introduced after } 2 \text { years following the retrofit } \\
\text { with a CCS system. } \\
\text { Decision Rule: } \\
\text { The CCS system is kept operating for a } \\
\text { year when the estimated cash flows for } \\
\text { the plant with an operating CCS system } \\
\text { are higher than without one in the } \\
\text { previous two consecutive years. }\end{array}$ \\
\hline
\end{tabular}




\begin{tabular}{|c|c|c|}
\hline Case F & $\begin{array}{l}\text { Constructional flexibility and } \\
\text { operational flexibility with pre- } \\
\text { investment for future plant retrofit } \\
\text { ("CCS-ready" plant) }\end{array}$ & $\begin{array}{l}\text { - The HP-CMR plant considers constructional } \\
\text { and operational flexibility options with pre- } \\
\text { investment for future plant retrofitting } \\
\text { purposes (CCS-ready plant). } \\
\text { - The constructional flexibility option } \\
\text { considered is introduced in the third year after } \\
\text { the introduction of the } \mathrm{CO}_{2} \text { tax. } \\
\text { Decision Rule: } \\
\text { - The plant is retrofitted with a CCS } \\
\text { system (enabled by pre-investment) when } \\
\text { the estimated cash flows for the plant } \\
\text { with an operating CCS system are higher } \\
\text { than without one in the previous two } \\
\text { consecutive years. } \\
\text { The operational flexibility option is } \\
\text { introduced after } 2 \text { years following the retrofit } \\
\text { with a CCS system. } \\
\text { Decision Rule: } \\
\text { The CCS system is kept operating for a } \\
\text { year when the estimated cash flows for } \\
\text { the plant with an operating CCS system } \\
\text { are higher than without one in the } \\
\text { previous two consecutive years. }\end{array}$ \\
\hline
\end{tabular}

* Notice that independently of the decision rule associated with the specific design flexibility option all plants have a total lifetime of 30 years.

\subsection{Economic performance assessment of design flexibility options under uncertainty}

The proposed economic performance evaluation of various potentially value-enhancing flexible design options for HP-CMRs is conducted in the presence of irreducible uncertainties. These sources of uncertainty enter the NPV-model as uncertain model inputs (random/stochastic variables), and therefore drive the valuation profile and assorted outcomes of this new technology option. As mentioned earlier, traditional economic performance assessment and valuation frameworks that generate single-point value estimates and uncertain model inputs are taken into account through fixed "average" values (rather than their own distribution profiles), quite often lead to unsatisfactory and potentially misleading performance outcome characterization and appraisals due to the "flaw of 
averages" [40,41]. Consequently, Monte Carlo techniques are integrated into the proposed economic assessment framework through which the potential challenges associated with the "flaw of averages" are effectively overcome while the simultaneous inclusion of various sources of irreducible uncertainty as multiple model input (random) variables (as opposed to the conventional sensitivity analysis) becomes feasible for all the flexibility options considered in this study. As a result, full distribution profiles of economic performance outcomes for HP-CMR plants endowed with design flexibility are derived in the presence of uncertainty. The derived profiles are amenable to potentially insightful statistical characterization and analysis, risks and opportunities that can be identified and actively managed through flexibility, and thus, potentially informing efforts to design incentives that could accelerate the realization of technology demonstration plants at the commercial scale.

According to the methodology followed in this study, all the uncertain model input variables are first identified and reasonable probabilistic representations through appropriately selected distribution profiles are assigned to them. Applying standard Monte Carlo techniques and performing random sampling from the above distributions, model input uncertainties are propagated through the NPV-model, and distribution profiles for the NPV are generated that can be statistically/probabilistically characterized. It should be pointed out that the expected value of the sample of NPV values generated through Monte Carlo simulations constitutes an unbiased estimator of the NPV expected value, and therefore, this is the main reason that the "flaw of averages" can be safely avoided within the proposed context $[23,40]$. In addition, the above probabilistic distribution profiles can be also viewed as "risk-reward/opportunity" profiles that enable the quantification of "risks/rewards" through the "value at risk" and the "value at opportunity" at pre-specified levels, which are extensively used as financial evaluative tools/indicators in risk management and investment planning $[9,29,32,40]$. In the present study, the "value at risk" is denoted as $\mathrm{P}_{5}$, and it is characterized as a threshold-value at a probabilistic level of 5\%, indicating that there is a $5 \%$ probability of generating a NPV lower than the $\mathrm{P}_{5}$ threshold-value. Similarly, the "value at opportunity" is represented by $\mathrm{P}_{95}$ to show that there is $5 \%$ probability to generate a NPV higher than the $\mathrm{P}_{95}$ threshold-value. Please notice that the lack of pertinent accumulated operating experience and the inevitable paucity of reliable data create significant economic performance evaluation challenges. Four types of probability distributions for the uncertain model input variables were considered in this study: normal distribution (ND), simple uniform distribution (SUD), triangular distribution (TD), and 
bootstrap distribution or re-sampling method (BD). Normal or Gaussian distribution profiles are symmetrically continuous outlines with a bell-shaped probability density function; in the present study, a normal distribution with mean 0 and standard deviation 1 is used to capture the Standard Brownian Motion and the associated increment random variable in the Wiener process that we considered to model regulatory uncertainty pertaining to the $\mathrm{CO}_{2}$ emission tax and its growth trajectory [39,40]. Triangular distribution profiles have a probability density function shaped like a triangle, defined by a model input's minimum, most likely, and maximum values. Triangular profiles are generally applied for cost estimation and risk assessments purposes with little knowledge about the model input outside the domain of approximate estimates related to its minimum, most likely, and maximum values $[9,40,42,43]$. Simple uniform or rectangular distribution profiles have a rectangular probability density function defined by two parameters, the model input's minimum and maximum values $[29,32,40,44,45]$. These profiles usually take into consideration reasonable ranges of values for the model input under consideration. It should be pointed out that, in the absence of any reliable data at the commercial scale, the above simple uniform and triangular distribution forms considered in this study span the range of estimates reported in recent comprehensive studies/reports (cited in the list of bibliographical references). Finally, in the presence of available historical data, the aforementioned bootstrap distribution profiles commonly used in cost estimation and risk assessment studies were derived using standard re-sampling methods $[9,32,40,46,47]$.

The sequence of steps of the Monte Carlo simulation procedure followed in this study is depicted in Figure 3. The software package XLSim was used to conduct the Monte Carlo simulation studies with $10^{4}$ runs each time and by taking into consideration all 40 uncertain model inputs simultaneously, as listed along with their corresponding probability distributions in Table 2 . The above uncertain input variables can be classified into the following main categories: i) basic economic parameters (interest rates, inflation rates, cost of capital, corporate taxes, etc.), ii) detailed cost components of the total capital investment and total product cost (following standard procedures as delineated in Peters and Timmerhaus [31]), as well as all other uncertain inputs related to cash flows such as (hydrogen price, carbon tax, plant availability factor, etc. Furthermore, please notice that in the absence of any accumulated operating experience of this new technology option at the commercial scale there is a dearth of pertinent technical data. In light of the above, the present study's primary aim is to present a methodological framework for the evaluation of flexible design options and identify 
zones/ranges of potential economic risks and opportunities in the presence of uncertainty rather than generating single-point cost/value-estimates. Within such a context, the associated probability distribution profiles (uniform, triangular, bootstrap) take into account reasonable and rather conservative ranges of values for all model inputs under consideration. Finally, a more detailed discussion on the structural components of the proposed NPV-model for HP-CMR plants can be found in an earlier piece of research work [9]. 


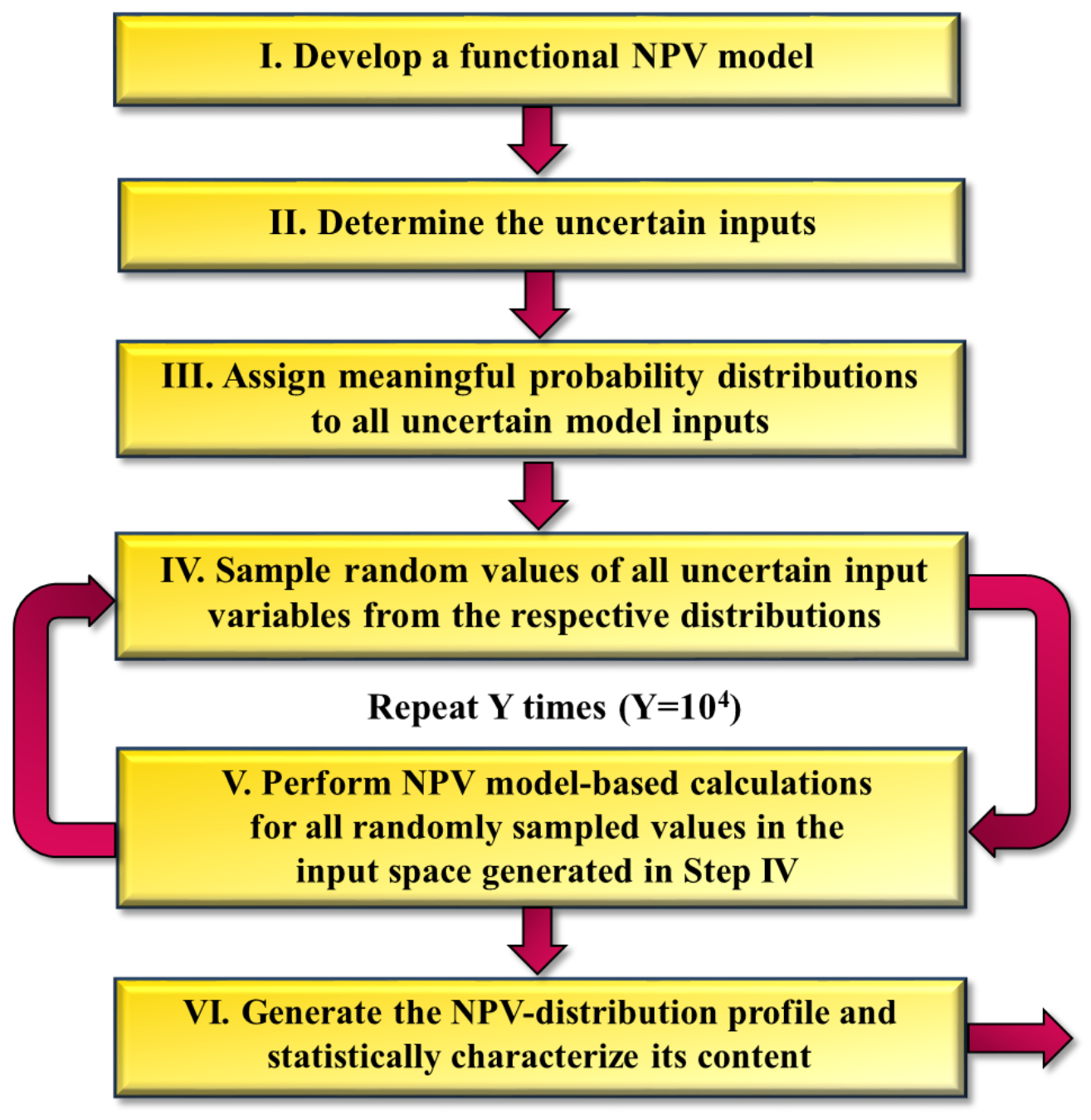

Figure 3. Sequence of methodological steps of the Monte Carlo simulation procedure. 
Table 2. Probability distributions corresponding to various uncertain model inputs*

\begin{tabular}{|c|c|c|c|}
\hline Uncertainty driver & Minimum & Most likely & Maximum \\
\hline Pd unit price $[\$ / g], B D$ & \multicolumn{3}{|c|}{$\begin{array}{l}\text { Historical data from 2011-2015, } \\
\text { www.kitco.com }\end{array}$} \\
\hline Au unit price $[\$ / g], B D$ & \multicolumn{3}{|c|}{$\begin{array}{l}\text { Historical data from 2011-2015, } \\
\text { www.kitco.com }\end{array}$} \\
\hline Labor cost per hour $[\$ / h], B D$ & \multicolumn{3}{|c|}{ Historical data from 2011-2015, www.bls.gov } \\
\hline Coal price per unit [\$/tonne], BD & \multicolumn{3}{|c|}{ Historical data from 2011-2015, www.eia.gov } \\
\hline Inflation rate, $\mathrm{BD}$ & \multicolumn{3}{|c|}{ Historical data from 2010-2014, www.bls.gov } \\
\hline \multirow[t]{3}{*}{$\mathrm{CO}_{2}$ transport \& storage costs per unit [\$/tonne], BD } & \multicolumn{3}{|c|}{$\begin{array}{l}\text { Depend on location of basins, } \\
\text { www.netl.doe.gov }\end{array}$} \\
\hline & Illinois & $\begin{array}{l}\text { ast } \\
\text { exas }\end{array}$ & $\begin{array}{l}\text { Powder } \\
\text { River }\end{array}$ \\
\hline & 11 & 16 & 24 \\
\hline \multirow[t]{3}{*}{$\mathrm{H}_{2}$ delivery cost per unit $[\$ / \mathrm{kg}], \mathrm{BD}$} & \multicolumn{3}{|c|}{$\begin{array}{l}350 \text { bar } \mathrm{H}_{2} \text { dispensing pathways (2013), } \\
\text { www.hydrogen.energy.gov }\end{array}$} \\
\hline & Tube trailer & $\begin{array}{l}\text { Pipeline-tube } \\
\text { trailer }\end{array}$ & Pipeline \\
\hline & 3.00 & 3.16 & 4.44 \\
\hline $\begin{array}{l}\text { 316L PSS support price per unit }\left[\$ / \mathrm{cm}^{2} \text { for a } 24 \mathrm{~cm}^{2}\right. \\
\text { support area], TD }\end{array}$ & 10.2 & 11.3 & 12.4 \\
\hline $\mathrm{Pd} / \mathrm{Au}$ membrane lifetime [year], $\mathrm{TD}^{\mathrm{a}}$ & 1 & 3 & 5 \\
\hline Nominal discount rate for HP-CMR plant, TD & $14.4 \%$ & $16.0 \%$ & $17.6 \%$ \\
\hline Combined state and local sales tax rates, TD & $0.0 \%$ & $6.4 \%$ & $9.5 \%$ \\
\hline Ratio for market value of plant after 30 years, $\mathrm{TD}^{\mathrm{b}}$ & $13.5 \%$ & $15.0 \%$ & $16.5 \%$ \\
\hline $\mathrm{H}_{2}$ selling price $[\$ / \mathrm{kg}], \mathrm{TD}$ & 9 & 10 & 11 \\
\hline Initial $\mathrm{CO}_{2}$ tax rate (start at 2017) [\$/tonne], TD & 27 & 30 & 33 \\
\hline Expected growth rate of $\mathrm{CO}_{2} \operatorname{tax}(\mu)$, TD & $5.4 \%$ & $6 \%$ & $6.6 \%$ \\
\hline Volatility of $\mathrm{CO}_{2}$ tax rate $(\sigma), \mathrm{UD}$ & 0 & & $20 \%$ \\
\hline Random variable used in the Standard Brownian & Mean & & ndard deviation \\
\hline Motion, ND & 0 & 1 & \\
\hline Capacity factor for HP-CMR plants without CCS, TD & $80 \%$ & $85 \%$ & $90 \%$ \\
\hline Capacity factor for HP-CMR plants with CCS, TD & $75 \%$ & $80 \%$ & $85 \%$ \\
\hline Extra O\&M cost for starting up the plant [\$], UD & $4,000,000$ & & $5,000,000$ \\
\hline Output de-rating factor without pre-investment, UD & $5 \%$ & & $10 \%$ \\
\hline Output de-rating factor with pre-investment, UD & 0 & & $5 \%$ \\
\hline Ratio for Installation, $\mathrm{UD}^{\mathrm{c}}$ & $25.0 \%$ & & $55.0 \%$ \\
\hline Ratio for instrumentation and controls, installed, $U^{c}$ & $8.0 \%$ & & $50.0 \%$ \\
\hline Ratio for piping, installed, $U^{c}$ & $10.0 \%$ & & $80.0 \%$ \\
\hline Ratio for electrical, installed, $\mathrm{UD}^{\mathrm{c}}$ & $10.0 \%$ & & $40.0 \%$ \\
\hline
\end{tabular}




\begin{tabular}{|c|c|c|}
\hline Ratio for buildings, process and auxiliary, $\mathrm{UD}^{\mathrm{c}}$ & $10.0 \%$ & $70.0 \%$ \\
\hline Ratio for service facilities and yard improvements, $\mathrm{UD}^{\mathrm{c}}$ & $40.0 \%$ & $100.0 \%$ \\
\hline Ratio for land, $U^{c}$ & $4.0 \%$ & $8.0 \%$ \\
\hline Ratio for engineering and supervision, $\mathrm{UD}^{\mathrm{d}}$ & $5.0 \%$ & $30.0 \%$ \\
\hline Ratio for legal expenses, $U^{b}$ & $1.0 \%$ & $3.0 \%$ \\
\hline Ratio for construction expense and contractor's fee, $\mathrm{UD}^{\mathrm{b}}$ & $10.0 \%$ & $20.0 \%$ \\
\hline Ratio for contingency, UD ${ }^{b}$ & $5.0 \%$ & $15.0 \%$ \\
\hline Ratio for insurance, $\mathrm{UD}^{\mathrm{b}}$ & $0.4 \%$ & $1.0 \%$ \\
\hline Ratio for working capital, $\mathrm{UD}^{\mathrm{e}}$ & $10.0 \%$ & $20.0 \%$ \\
\hline Ratio for financing interest, $\mathrm{UD}^{\mathrm{e}}$ & $6.0 \%$ & $10.0 \%$ \\
\hline Ratio for plant overhead costs, $U^{f}$ & $5.0 \%$ & $15.0 \%$ \\
\hline Ratio for patents and royalties, $U^{f}$ & $0.0 \%$ & $6.0 \%$ \\
\hline Ratio for administrative costs, $\mathrm{UD}^{\mathrm{f}}$ & $2.0 \%$ & $5.0 \%$ \\
\hline Ratio for marketing costs, $U^{f}$ & $2.0 \%$ & $6.0 \%$ \\
\hline \multicolumn{3}{|c|}{$\begin{array}{l}\mathrm{BD}=\text { Bootstrap distribution }, \mathrm{TD}=\text { Triangular distribution, } \mathrm{UD}=\text { Uniform distribution, } \\
\mathrm{ND}=\text { Normal distribution }\end{array}$} \\
\hline \multicolumn{3}{|c|}{$\begin{array}{l}\text { *Otherwise unspecified references were obtained from Peters et al. [31]. } \\
{ }^{\text {a }} \text { Based on available lab-scale data and estimates reported in the literature, } \\
{ }^{b} \text { Based on fixed capital investment, }{ }^{\mathrm{c}} \text { Based on purchased equipment cost, }{ }^{\mathrm{d}} \text { Based on direct cost, } \\
{ }^{\mathrm{e}} \text { Based on total capital investment, }{ }^{\mathrm{f}} \text { Based on total product cost. }\end{array}$} \\
\hline
\end{tabular}

\section{Main Results and Discussion}

As mentioned earlier, two different types of potentially value-enhancing design flexibility options are proposed and classified as operational and constructional flexibility options respectively (Table 1). In this section, through the integration of standard Monte Carlo simulation methods, the cumulative probability distribution profiles of the Net Present Value (NPV) (along with the corresponding Expected Net Present Values (ENPVs)) for various flexibility options are presented and graphically depicted that are amenable to insightful statistical characterization. In addition, standard financial metrics and tools derived from the above NPV distribution profiles are used to comparatively evaluate the performance of the various design flexibility options introduced in response to future regulatory action on $\mathrm{CO}_{2}$ emissions in the form of a direct tax that is mathematically represented through a Geometric Brownian Motion model. Finally, a sensitivity analysis with respect to various model inputs in the above $\mathrm{CO}_{2}$ tax scenarios is conducted and Tornado diagrams are developed that 
generate additional pieces of valuable information about the performance characteristics of the HPCMR plant under the proposed flexibility options.

\subsection{Operational Flexibility for the HP-CMR Plant in the Presence of $\mathrm{CO}_{2}$ tax}

The cumulative probability distribution profiles of the NPV with their corresponding ENPVs for Case A (the baseline case) and Case B (operational flexibility option) under an initial tax rate of $\$ 30$ per tonne of $\mathrm{CO}_{2}$ are presented in Figure 4 along with a set of pertinent financial metrics summarized in Table 3. The initial $\mathrm{CO}_{2}$ tax rate of $\$ 30$ per tonne of $\mathrm{CO}_{2}$ is consensually recognized as a reasonable initial estimate and regulatory "price-signal" to be potentially internalized by energy markets as reflected on relevant project valuation studies [9]. Its choice is motivated by the fact that $\mathrm{CO}_{2}$ abatement costs lower than $\$ 30$ per tonne of $\mathrm{CO}_{2}$ can be currently achieved using more mature technologies, and thus regulatory action on the above level helps incentivize plant owners/operators to invest in CCS systems [48]. In Figure 4, both cases have similar NPV performance characteristics with a $30 \%$ probability for the NPV to be higher than $1.5 \mathrm{~B} \$$. Case A has an $11 \%$ probability to generate a NPV lower than $-0.5 \mathrm{~B} \$$ while there is a $10 \%$ probability for Case B to generate a NPV lower than -0.5 $\mathrm{B}$ \$, implying that the plant with the operational flexibility option has lower downside risks than the baseline case. Table 3 shows that the ENPV generated in Case B is higher than in Case A, demonstrating that the operational flexibility option has a potentially value-enhancing capacity in response to regulatory action on carbon. In addition, it can be inferred that Case B exhibits higher security/robustness in economic performance than Case A since the spread (defined as $\mathrm{P}_{95}-\mathrm{P}_{5}$ ), the probability of loss, as well as the standard deviation of the corresponding NPV distribution profile are lower in Case B. These traits can be attributed to the fact that the impact of certain negative cash flows under more stringent/demanding regulatory conditions throughout the plant's economic life can be effectively reduced and better managed under the operational flexibility option. Indeed, such a flexibility option allows a pro-active adjustment to evolving regulatory requirements as the associated uncertainties get gradually resolved and the management team exercises the above option (thus minimizing downside economic risk). 


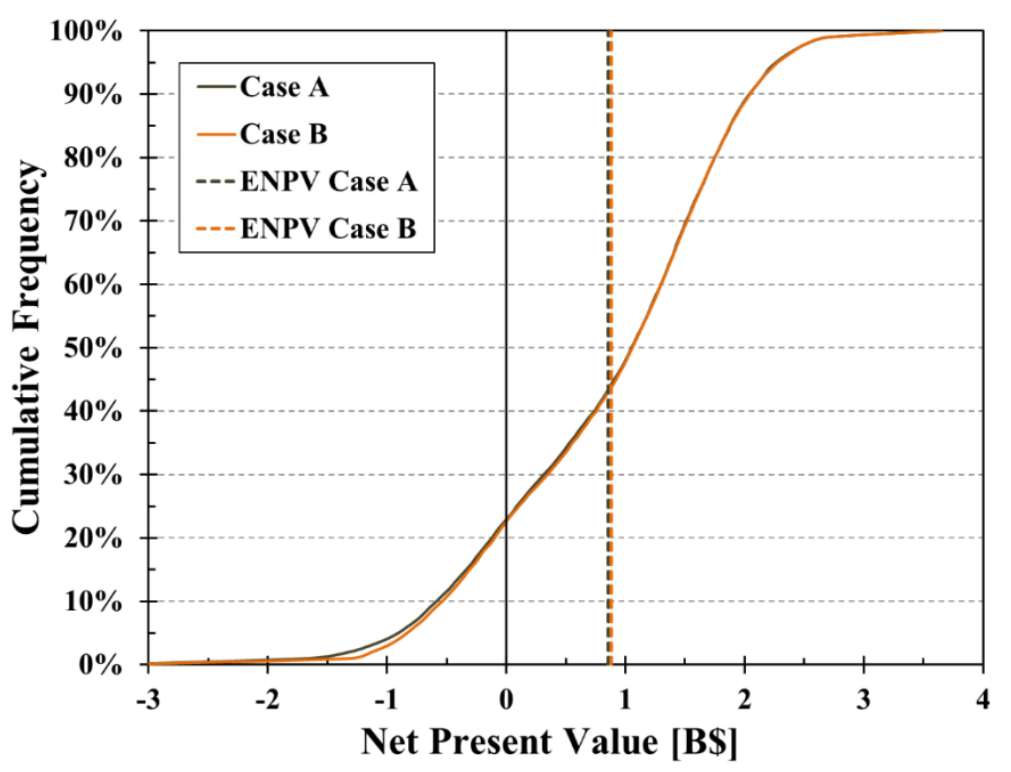

Figure 4. Cumulative probability distribution profiles of the Net Present Value (NPV) along with the Expected Net Present Value (ENPV) for Cases $A$ and $B$ under an initial tax rate of $\$ 30$ per tonne of $\mathrm{CO}_{2}$.

Table 3. Comparison of various financial metrics for Cases A and B.

\begin{tabular}{lll}
\hline & Case A & Case B \\
\hline $\mathrm{P}_{95}[\mathrm{~B} \$]$ & 2.26 & 2.27 \\
$\mathrm{ENPV}[\mathrm{B} \$]$ & 0.86 & 0.88 \\
$\mathrm{P}_{5}[\mathrm{~B} \$]$ & -0.91 & -0.83 \\
Standard deviation $[\mathrm{B} \$]$ & 1.01 & 0.98 \\
Spread $[\mathrm{B} \$]$ & 3.17 & 3.11 \\
Probability of loss & $23 \%$ & $22 \%$ \\
Initial ETCI (CAPEX measure) $[\mathrm{B} \$]^{*}$ & 1.52 & 1.52 \\
\hline
\end{tabular}

* ETCI: Expected Total Capital Investment; CAPEX: Capital Expenditure 


\subsection{Operational Flexibility - Inclusion of a CCS System in the Initial Design Phase}

In this sub-section, a design flexibility option is evaluated and discussed through Cases $\mathrm{C}$ and D where a CCS system is introduced in the initial design phase. Figure 5 shows the cumulative probability distribution profiles of the NPV for the various options in the absence and also in the presence of a $\mathrm{CO}_{2}$ tax, while Table 4 summarizes the financial metrics derived from the above simulation results and the statistical characterization of the corresponding NPV-profiles.

As shown in Figure 5 and Table 4, in the absence of $\mathrm{CO}_{2}$ tax, Case A displays more appealing NPV-performance characteristics than Case C and Case D, a feature which is in agreement with investors' hesitancy to invest in a technology option with CCS when regulatory compliance costs are not involved. However, in the presence of $\mathrm{CO}_{2}$ tax, the NPV-profile of Case A shows a significant reduction in the ENPV, $\mathrm{P}_{95}$ and $\mathrm{P}_{5}$, accompanied also by a higher probability of loss. Please notice now that Case $\mathrm{C}$ and Case D are less sensitive to $\mathrm{CO}_{2}$ taxes, displaying higher ENPVs, smaller spreads, and lower probability of loss. This result can be attributed to the fact that the NPV distribution profiles in the presence of $\mathrm{CO}_{2}$ tax critically depend on the "carbon tax penalty" (i.e. regulatory compliance cost component) which is computed through the $\mathrm{CO}_{2}$ tax rate and the amount of $\mathrm{CO}_{2}$ emissions. Furthermore, as shown in Figure 5 and Table 4 Case D displays a 35\% higher ENPV and a 33\% lower probability of loss than Case $\mathrm{C}$, demonstrating that the proposed operational flexibility option can effectively further improve economic performance in response to uncertain $\mathrm{CO}_{2}$ tax scenarios. Indeed, under the flexibility option the "carbon tax penalty" and the assorted regulatory uncertainty can be significantly better managed by running the CCS in accordance to the option's decision-rule (Table 1) while reducing $\mathrm{CO}_{2}$ emissions. Following this flexible operating strategy where the optionality element in the management team's decision-making to actively respond to the evolving regulatory regime is explicitly recognized, clearly leads to enhanced economic performance over the HP-CMR plant's lifetime. 


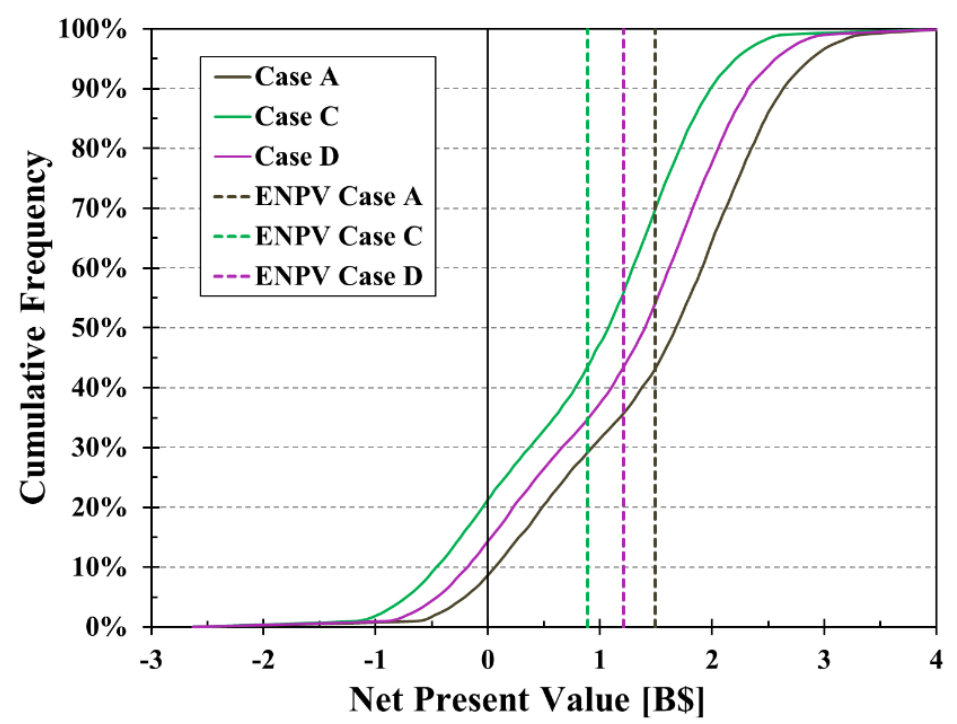

(a)

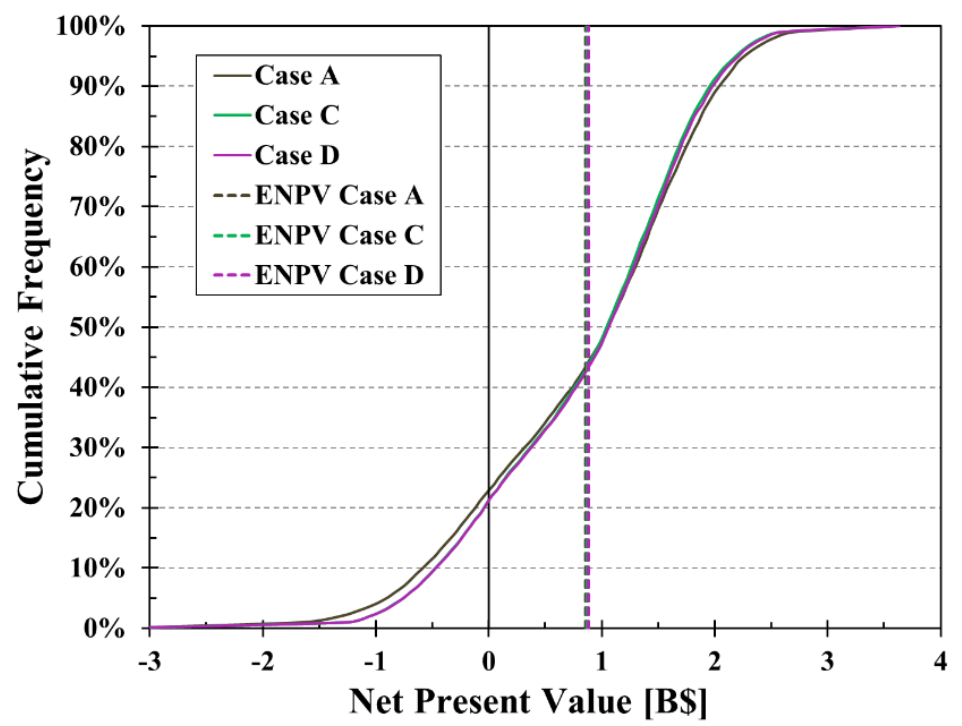

(b)

Figure 5. Cumulative probability distribution profiles of the NPV with the ENPV for various constructional flexibility options with inclusion of a CCS system in the initial design phase (a) in the absence of $\mathrm{CO} 2$ tax and (b) under an initial tax rate of $\$ 30$ per tonne of $\mathrm{CO}_{2}$. 
Table 4. Comparison of various financial metrics for Cases A, C and D.

\begin{tabular}{|c|c|c|c|c|c|c|}
\hline & \multicolumn{3}{|c|}{ In the absence of $\mathrm{CO}_{2}$ tax } & \multicolumn{3}{|c|}{ In the presence of $\mathrm{CO}_{2}$ tax } \\
\hline & Case A & Case C & Case D & Case A & Case C & Case D \\
\hline $\mathrm{P}_{95}[\mathrm{~B} \$]$ & 2.88 & 2.21 & 2.56 & 2.26 & 2.19 & 2.21 \\
\hline ENPV $[\mathrm{B} \$]$ & 1.49 & 0.89 & 1.21 & 0.86 & 0.87 & 0.88 \\
\hline $\mathrm{P}_{5}[\mathrm{~B} \$]$ & -0.20 & -0.73 & -0.45 & -0.91 & -0.76 & -0.76 \\
\hline Standard deviation $[\mathrm{B} \$]$ & 0.98 & 0.93 & 0.96 & 1.01 & 0.93 & 0.93 \\
\hline Spread $[\mathrm{B} \$]$ & 3.09 & 2.94 & 3.02 & 3.17 & 2.94 & 2.97 \\
\hline Probability of loss & $8 \%$ & $21 \%$ & $14 \%$ & $23 \%$ & $22 \%$ & $22 \%$ \\
\hline $\begin{array}{l}\text { Initial ETCI (CAPEX } \\
\text { measure) }[\mathrm{B} \$]\end{array}$ & 1.52 & 1.57 & 1.57 & 1.52 & 1.57 & 1.57 \\
\hline
\end{tabular}

\subsection{Constructional and Operational Flexibility- Potential Inclusion of a CCS} System at a Later Stage

The strategic option of retrofitting the plant with a CCS system at a later stage (constructional flexibility) is evaluated and discussed in this sub-section. Figure 6 presents cumulative probability distribution profiles of the NPV for constructional flexibility options in the presence and absence of regulatory action on $\mathrm{CO}_{2}$ emissions, while Table 5 summarizes the financial metrics derived from the statistical characterization of the above NPV-profiles. Please notice that the expected service time for the CCS system (in Table 5) indicates how long the CCS system has been installed in the plant.

For the inclusion and engagement of a CCS system at a later stage without a pre-investment option that could operationally and economically facilitate this possible retrofit in the future ("CCSready" initial plant design) (Case E), the associated performance on the basis of ENPV, $\mathrm{P}_{95}, \mathrm{P}_{5}$, spread, and probability of loss in the absence of $\mathrm{CO}_{2}$ tax appears more attractive than in Case D (Figure 6 (a) and Table 5). This positive effect arises as retrofitting with a CCS system at a later stage reduces unnecessary capital investments and associated costs (such as fixed and variable O\&M costs) when $\mathrm{CO}_{2}$ tax is absent. However, in the presence of $\mathrm{CO}_{2}$ tax, Case D displays a superior NPV performance than Case E. The de-rating factor, generated by retrofitting with a CCS system at a later stage, for Case 
E induces a negative impact on the NPV performance by reducing the revenue from hydrogen sales. When comparing the variation in the NPV performance between the scenarios (in the absence of $\mathrm{CO}_{2}$ tax and in the presence of $\mathrm{CO}_{2} \operatorname{tax}$ ), the ENPV decreases by $47 \%$ in Case E, which is much higher than the $26 \%$ reduction in Case D. Simultaneously, the probability of loss increased from $8 \%$ to $24 \%$ for Case E, while for Case D the percentage increased from $14 \%$ to only $22 \%$, demonstrating the higher sensitivity of Case $\mathrm{E}$ to regulatory action, i.e. the $\mathrm{CO}_{2}$ tax. In light of the above results, the inclusion of a CCS system at a later stage should be more favorable at lower $\mathrm{CO}_{2}$ tax rates than in the initial design phase.

Case $\mathrm{E}$ and Case $\mathrm{F}$ are compared in the absence and presence of a $\mathrm{CO}_{2}$ tax in order to investigate the effect of pre-investment in a "CCS-ready" HP-CMR plant that could potentially facilitate the option of plant retrofitting and the accommodation of a CCS system at a later stage. Please notice that the expected value of the pre-investment cost is $\$ 33 \mathrm{M}$, which is obtained via Monte Carlo simulations. As presented in Figure 6 and Table 5, Case E displays superior NPV performance than Case $\mathrm{F}$ in the absence of $\mathrm{CO}_{2}$ tax; however, the NPV performance in Case $\mathrm{F}$ becomes more attractive than Case $\mathrm{E}$ in the presence of a $\mathrm{CO}_{2}$ tax. In particular, when considering the above preinvestment option, the ENPV increases by $14 \%$ and the probability of loss is reduced by $3 \%$, since the pre-investment option can provide a type of "insurance" against downside risk associated with more stringent future regulatory action and heavier compliance costs as well as enhance upside opportunities when regulatory conditions allow.

Under the baseline scenario, Case F exhibits the most appealing economic performance profile over other cases in terms of both ENPV and probability of loss, indicating that the combination of constructional flexibility and operational flexibility modes with pre-investment in a "CCS-ready" plant structure represents an improved way to manage regulatory uncertainty and add value to the HP-CMR plant. Furthermore, Case F also shows significant reduction in downside risks and enhancement in upside opportunities in the presence of these uncertainties. However, for different $\mathrm{CO}_{2} \operatorname{tax}$ scenarios, Case F may exhibit different economic performance characteristics, since every case of flexible design exhibits a different NPV performance profile when key parameters in the probabilistic modeling of the various uncertain inputs (such as the initial $\mathrm{CO}_{2}$ tax rate) assume different values. In order to understand the robustness or sensitivity of the economic evaluation outcomes and characterization of 
the various flexible design options to key parameters such as the initial $\mathrm{CO}_{2}$ tax rate, the expected growth rate of the $\mathrm{CO}_{2}$ tax, as well as the year of introducing the $\mathrm{CO}_{2}$ tax that underlie the various $\mathrm{CO}_{2}$ tax scenarios, a sensitivity analysis is conducted followed by a detailed discussion in the next subsection.



(a)

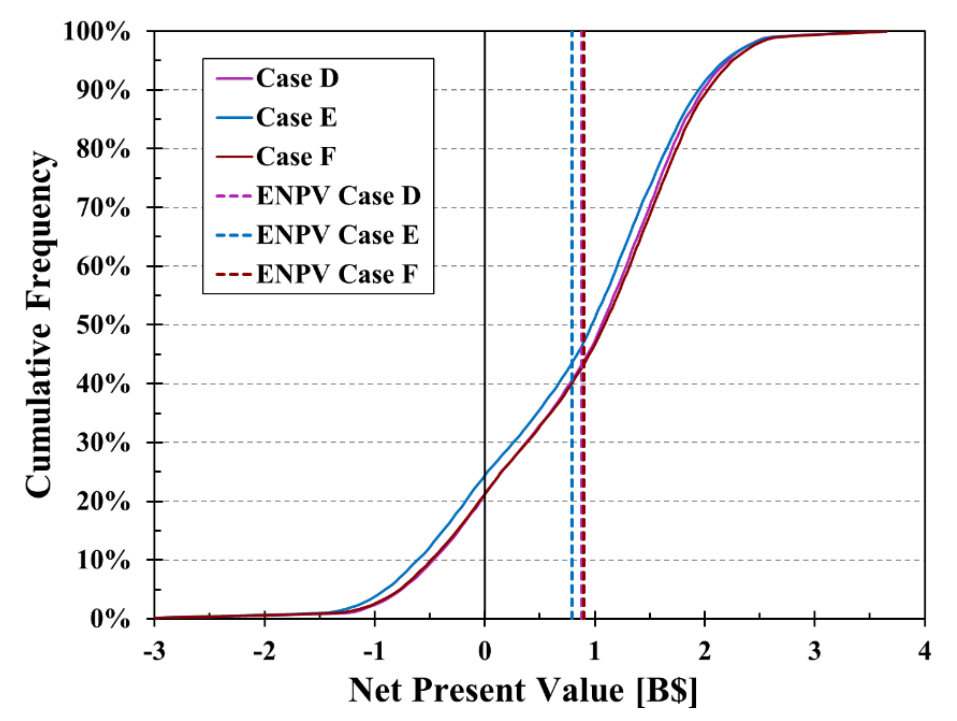

(b)

Figure 6. Cumulative NPV probability distribution profiles (with the associated ENPVs) for various constructional flexibility options with inclusion of a CCS system at a later stage (a) in the absence of $\mathrm{CO}_{2}$ tax and (b) under an initial tax rate of $\$ 30$ per tonne of $\mathrm{CO}_{2}$. 
Table 5. Comparison of various financial metrics for Cases D, E and F.

\begin{tabular}{|c|c|c|c|c|c|c|}
\hline & \multicolumn{3}{|c|}{ In the absence of $\mathrm{CO}_{2}$ tax } & \multicolumn{3}{|c|}{ In the presence of $\mathrm{CO}_{2}$ tax } \\
\hline & Case D & Case $\mathbf{E}$ & Case $\mathbf{F}$ & Case D & Case $\mathbf{E}$ & Case $\mathbf{F}$ \\
\hline $\mathrm{P}_{95}[\mathrm{~B} \$]$ & 2.56 & 2.88 & 2.85 & 2.21 & 2.18 & 2.25 \\
\hline $\mathrm{ENPV}[\mathrm{B} \$]$ & 1.21 & 1.49 & 1.45 & 0.88 & 0.79 & 0.90 \\
\hline $\mathrm{P}_{5}[\mathrm{~B} \$]$ & -0.45 & -0.20 & -0.24 & -0.76 & -0.90 & -0.77 \\
\hline Standard deviation [B $\$$ ] & 0.96 & 0.98 & 0.98 & 0.93 & 0.97 & 0.96 \\
\hline Spread $[\mathrm{B} \$]$ & 3.02 & 3.09 & 3.09 & 2.97 & 3.08 & 3.02 \\
\hline Probability of loss & $14 \%$ & $8 \%$ & $9 \%$ & $22 \%$ & $24 \%$ & $21 \%$ \\
\hline $\begin{array}{l}\text { Initial ETCI (CAPEX } \\
\text { measure) }[\mathrm{B} \$]\end{array}$ & 1.57 & 1.52 & 1.55 & 1.57 & 1.52 & 1.55 \\
\hline $\begin{array}{l}\text { Expected service time of } \\
\text { the CCS system [year] }\end{array}$ & 30.0 & 0.0 & 0.0 & 30.0 & 12.9 & 19.8 \\
\hline
\end{tabular}

\subsection{Sensitivity Analysis}

A sensitivity analysis was first conducted with respect to various initial $\mathrm{CO}_{2}$ tax rates in order to evaluate the robustness characteristics of the proposed economic performance evaluation framework for the various flexibility options to basic parameters used in the pertinent model of future regulatory action on $\mathrm{CO}_{2}$ emissions. Figure 7 presents the ENPV difference of HP-CMR plants with and without design flexibility options for various initial $\mathrm{CO}_{2}$ tax rates (from 0 to $\$ 60$ per tonne of $\mathrm{CO}_{2}$ ). The corresponding ENPV differences (Cases with design flexibility [B, C, D, E, F] - Baseline Case [A]) for various initial $\mathrm{CO}_{2}$ tax rates are also summarized in Table 6.

The ENPV difference between Case $\mathrm{B}$ and Case $\mathrm{A}$ is positive within the range of initial $\mathrm{CO}_{2}$ tax rates considered and gradually increases as the initial $\mathrm{CO}_{2}$ tax rate increases, indicating that the operational flexibility option is inherently advantageous and its value enhancing capabilities become more pronounced under higher initial $\mathrm{CO}_{2}$ tax rate scenarios. In cases where the inclusion of a CCS system in the initial design phase is considered (Case C and Case D), the ENPV difference changes 
from negative to positive. When the initial $\mathrm{CO}_{2}$ tax rate is higher than $\$ 25$ per tonne of $\mathrm{CO}_{2}$, including a CCS system in the initial design phase is an economically appealing option. Furthermore, Case D can mitigate losses to produce higher ENPVs than Case $\mathrm{C}$ when the initial $\mathrm{CO}_{2}$ tax is lower than $\$ 35$ per tonne of $\mathrm{CO}_{2}$. Including a CCS system in the initial design phase (Case C and Case D) becomes a more economically appealing option at higher initial $\mathrm{CO}_{2}$ tax rates, while retrofitting with a CCS system at a later stage (Case $\mathrm{E}$ and $\mathrm{Case} \mathrm{F}$ ) it becomes preferable as an option at lower initial $\mathrm{CO}_{2}$ tax rates. Specifically, when the initial $\mathrm{CO}_{2}$ tax rate is below $\$ 20$ per tonne of $\mathrm{CO}_{2}$, higher ENPVs can be produced by the inclusion of a CCS system at a later stage (Cases E and F) rather than in the initial design phase (Cases $\mathrm{C}$ and $\mathrm{D}$ ). In contrast, when the initial $\mathrm{CO}_{2}$ tax rate is higher than $\$ 30$ per tonne of $\mathrm{CO}_{2}$, higher ENPVs can be achieved by the inclusion of a CCS system in the initial design phase (Cases C and D).

At an initial $\mathrm{CO}_{2}$ tax rate in the range between $\$ 25$ and $\$ 35$ per tonne of $\mathrm{CO}_{2}$, Case $\mathrm{F}$ displays the most appealing ENPV-performance and the specific effect of the pre-investment option in a CCSready plant on ENPV-performance (and the inclusion of a CCS system at a later stage) is shown through a comparative evaluation of Case E and Case F (Figure 7 and Table 6). Notice that Case F generates a higher ENPV than Case $\mathrm{E}$ for initial $\mathrm{CO}_{2}$ tax rates above $\$ 15$ per tonne of $\mathrm{CO}_{2}$, suggesting that the pre-investment option remains the preferred option under the above regulatory scenario. 


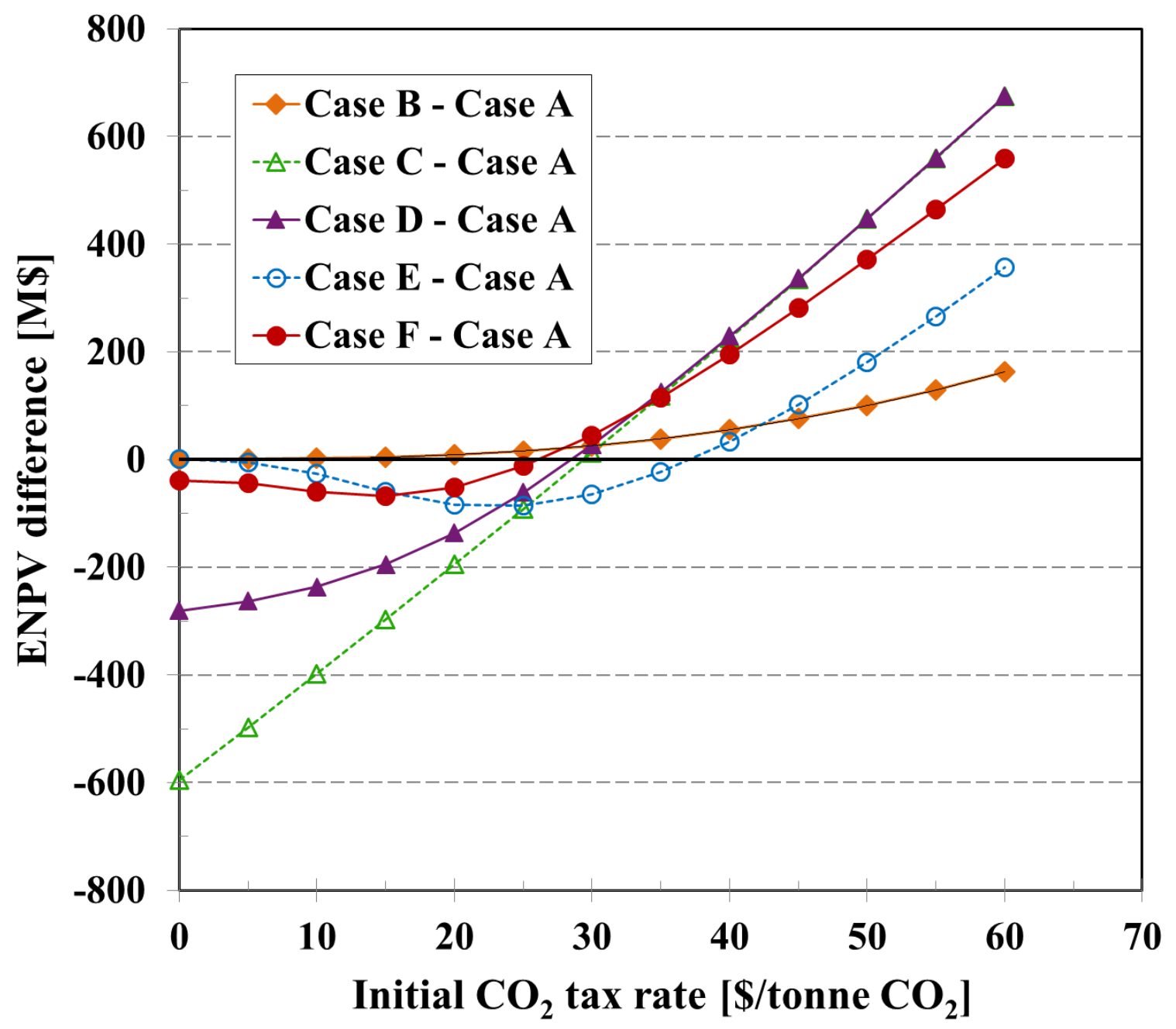

Figure 7. ENPV difference in cases with and without flexible design options under various initial $\mathrm{CO}_{2}$ tax rates 
Table 6. Summary of ENPV difference (M\$) in cases with and without flexible design options under various initial $\mathrm{CO}_{2}$ tax rates.

\begin{tabular}{|c|c|c|c|c|c|c|c|c|c|c|c|c|c|}
\hline \multirow{2}{*}{ ENPV difference } & \multicolumn{13}{|c|}{ Initial $\mathrm{CO}_{2}$ tax rate $\left[\$ /\right.$ tonne $\left.\mathrm{CO}_{2}\right]$} \\
\hline & $\mathbf{0}$ & 5 & 10 & 15 & 20 & 25 & 30 & 35 & 40 & 45 & 50 & 55 & 60 \\
\hline Case B - Case A & 0 & 1 & 2 & 4 & 9 & 16 & 26 & 39 & 55 & 76 & 101 & 129 & 163 \\
\hline Case C - Case A & -596 & -498 & -398 & -297 & -195 & -92 & 12 & 118 & 225 & 335 & 446 & 559 & 675 \\
\hline Case D - Case A & -281 & -263 & -237 & -195 & -136 & -61 & 27 & 125 & 229 & 337 & 447 & 560 & 675 \\
\hline Case E - Case A & 1 & -5 & -26 & -59 & -83 & -85 & -64 & -23 & 33 & 101 & 180 & 266 & 357 \\
\hline Case F - Case A & -39 & -45 & -60 & -67 & -51 & -12 & 45 & 116 & 196 & 281 & 371 & 464 & 560 \\
\hline
\end{tabular}


A sensitivity analysis was then conducted with respect to various $\mathrm{CO}_{2}$ tax growth rates (the drift term in the Geometric Brownian Motion model) to assess the robustness characteristics of the proposed economic performance evaluation framework for the various flexibility options. Figure 8 graphically depicts the ENPV difference in cases with and without flexible design options for an initial $\mathrm{CO}_{2}$ tax rate of $\$ 30$ per tonne of $\mathrm{CO}_{2}$ and various tax growth rates various, while the corresponding numerical results are summarized in Table 7.

As shown in Figure 8 and Table 7, the ENPV difference between Case B and Case A is positive, and gradually increases in magnitude with higher expected growth rates. Indeed, this flexibility option can effectively enhance NPV performance within the range of expected growth rates of $\mathrm{CO}_{2}$ tax considered in this study. For the options where the inclusion of a CCS system takes place in the initial design phase (Case C and Case D), the ENPV difference increases with higher growth rates, indicating that the flexible option appears as more economically appealing under higher $\mathrm{CO}_{2}$ tax growth rates. In particular, Case D exhibits a higher ENPV and an increase in the corresponding ENPV difference with a reduction in the tax growth rate, implying that the operational flexibility option for the CCS system can further reduce economic losses under less stringent $\mathrm{CO}_{2}$ tax scenarios and lighter regulatory compliance costs.

For the inclusion of a CCS system at a later stage (Case E and Case F), pertinent results in cases with and without the pre-investment option in a CCS-ready plant are also shown within the range of tax growth rates considered in the present study. The ENPV difference between Case $\mathrm{E}$ and Case $\mathrm{A}$ is at its minimum value when the expected growth rate is $5 \%$. This is a manifestation of the sensitivity of Case E when the expected tax growth rate falls below 5\%. Nonetheless, Case E becomes less sensitive than Case A when the expected growth rate is higher than $5 \%$. Finally, when the expected growth rate is greater than $7.5 \%$, the ENPV difference becomes positive, indicating that the economic (regulatory compliance) burden produced by the "carbon tax penalty" in Case A is now substantial when compared to the one produced by the inevitable de-rating effect in Case $\mathrm{E}$ due to potential retrofit.

In the case of a potential inclusion of a CCS system at a later stage, Case E clearly displays a superior ENPV performance profile than Cases C and D, when the expected tax growth rate is lower than 4\%. Nonetheless, Case F exhibits a more appealing ENPV performance than Case $C$ and Case D under the range of expected tax growth rates considered (Figure 8 and 
Table 7). In particular, an increase in the corresponding ENPV difference between Case F and Case $\mathrm{C} /$ Case $\mathrm{D}$ becomes more pronounced under less stringent $\mathrm{CO}_{2}$ tax scenarios and lighter regulatory compliance costs. Even though the inclusion of a CCS system in the initial design phase is preferred under high expected growth rate scenarios, insurance provided by the preinvestment option could make the inclusion of a CCS system at a later stage more economically favorable as demonstrated by Case F.

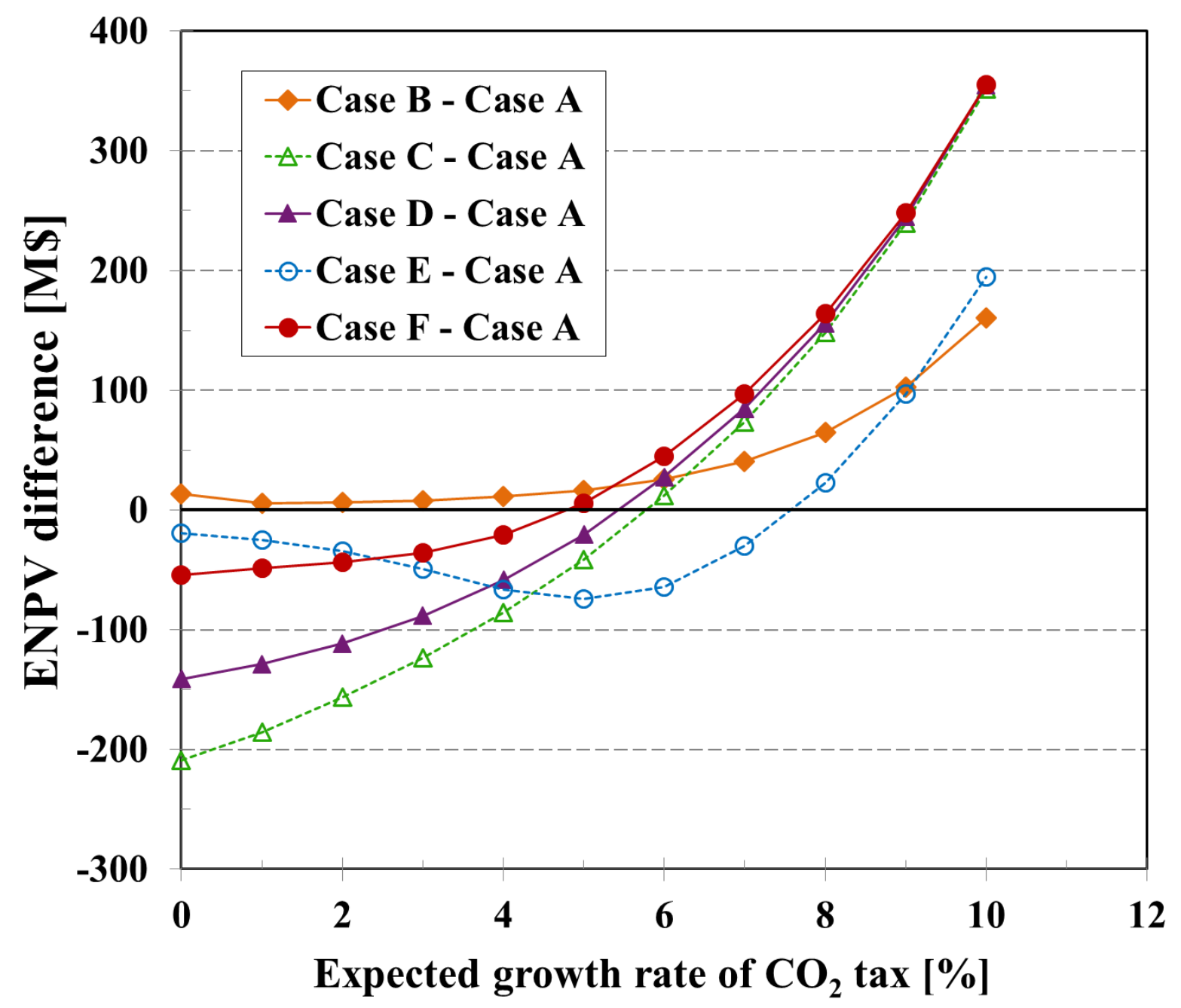

Figure 8. ENPV difference in cases with and without flexible design options under various $\mathrm{CO}_{2}$ tax growth rates. 
Table 7. Summary of ENPV difference (M\$) in cases with and without flexible design options under various $\mathrm{CO}_{2}$ tax growth rates.

\begin{tabular}{|c|c|c|c|c|c|c|c|c|c|c|c|}
\hline \multirow{2}{*}{ ENPV difference } & \multicolumn{11}{|c|}{ Expected growth rate of $\mathrm{CO}_{2}$ tax [\%] } \\
\hline & $\mathbf{0}$ & 1 & 2 & 3 & 4 & 5 & 6 & 7 & 8 & 9 & 10 \\
\hline Case B - Case A & 13 & 5 & 6 & 8 & 11 & 17 & 26 & 41 & 65 & 102 & 160 \\
\hline Case C - Case A & -209 & -185 & -156 & -124 & -86 & -41 & 12 & 73 & 148 & 240 & 352 \\
\hline Case D - Case A & -141 & -129 & -111 & -88 & -59 & -21 & 27 & 84 & 156 & 245 & 355 \\
\hline Case E - Case A & -20 & -25 & -34 & -49 & -67 & -74 & -64 & -30 & 23 & 97 & 195 \\
\hline Case F - Case A & -54 & -49 & -43 & -36 & -21 & 6 & 45 & 97 & 164 & 248 & 355 \\
\hline
\end{tabular}


The year of $\mathrm{CO}_{2}$ tax introduction is another factor and parameter in our study that influences the HP-CMR plant's economic performance profile under design flexibility. Therefore, a sensitivity analysis was also conducted with respect to different years of introducing the $\mathrm{CO}_{2}$ tax to assess the robustness characteristics of the proposed economic performance evaluation framework for the various flexibility options considered for an HP-CMR plant. In Figure 9 the ENPV difference in cases with and without flexible design options under the baseline scenario (the initial $\mathrm{CO}_{2}$ tax rate is $\$ 30$ per tonne of $\mathrm{CO}_{2}$ and the expected growth rate of $\mathrm{CO}_{2}$ tax is 6\%) for different years of introducing the $\mathrm{CO}_{2}$ tax is graphically depicted. The pertinent results are summarized in Table 8.

Figure 9 and Table 8 show that the ENPV difference between Case B and Case A is positive and gradually decreases with shorter tax periods. Indeed, the operational flexibility option for plant operation can provide insurance to reduce losses in the presence of a $\mathrm{CO}_{2}$ tax. For the flexibility options considering the inclusion of a CCS system in the initial design phase (Case C and Case D), the corresponding ENPV difference narrows with shorter tax periods. Furthermore, Case C displays a lower ENPV than Case D and the ENPV difference significantly narrows when the time-length of the tax period decreases. In addition, even though Case D captures an operational flexibility option for the operation of the CCS system, the ENPV difference remains negative if the tax period is shorter than 22 years.

Case E and Case F are also compared to study the effect of the pre-investment option in a CCSready plant on the NPV performance profile for various years of introducing the $\mathrm{CO}_{2}$ tax. As presented in Figure 9 and Table 8, the ENPV difference between Case E and Case A is wider than between Case $\mathrm{F}$ and Case $\mathrm{A}$ when the tax period is under 17 years; this implies that the pre-investment option might be unnecessary to be introduced in a shorter tax period. Please notice that the potential economic benefits associated with the pre-investment option become less pronounced as the time-length of the tax period decreases, resulting in a less satisfactory NPV performance profile in Case F. This can be attributed to the "competing effect" of two terms/components in the calculation of cash flows, namely between the carbon penalty and the capacity factor that enters the annual revenue estimation term. Furthermore, notice that Case E and Case F show superior ENPV performance than Case C and Case D when the tax period is shorter than 22 years (Figure 9 and Table 8). This indicates that cases accommodating the inclusion of a CCS system in the initial design phase appear more sensitive to the time-length of the regulatory tax period. 


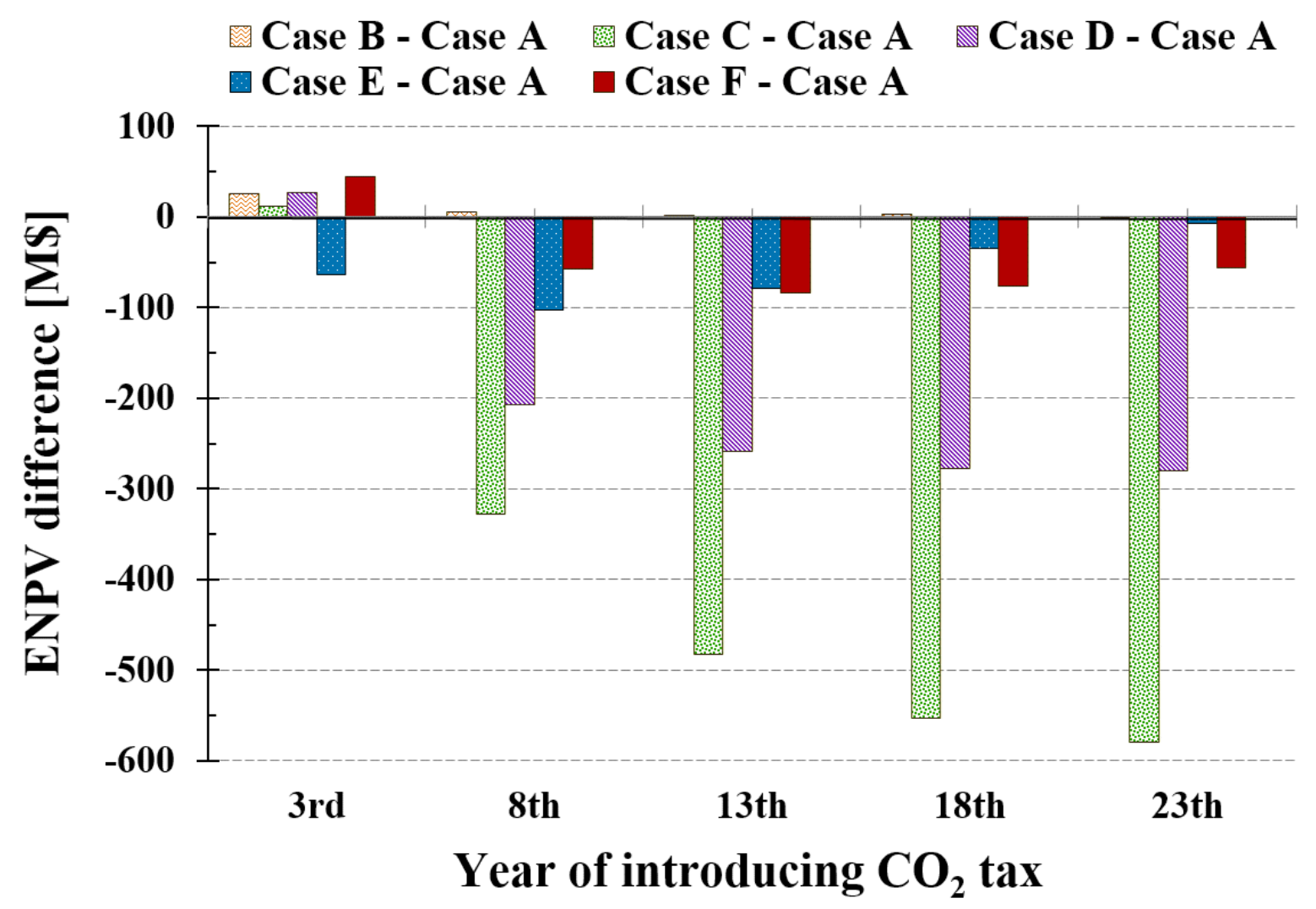

Figure 9. ENPV difference in cases with and without flexible design options at different years of introducing the $\mathrm{CO}_{2}$ tax.

Table 8. Summary of ENPV difference (M\$) in cases with and without flexible design options at different years of introducing the $\mathrm{CO}_{2}$ tax.

\begin{tabular}{llllll}
\hline \multirow{2}{*}{ ENPV difference } & \multicolumn{2}{l}{ Year of introducing $\mathbf{C O}_{\mathbf{2}}$ tax } & \multicolumn{1}{l}{ 19th } & 23th \\
\cline { 2 - 6 } & 3rd & 8th & 13th & 18th & 0 \\
\hline Case B - Case A & 26 & 6 & 1 & 4 & -579 \\
Case C - Case A & 12 & -328 & -482 & -554 & -280 \\
Case D - Case A & 27 & -208 & -258 & -277 & -7 \\
Case E - Case A & -64 & -102 & -78 & -35 &
\end{tabular}


Please notice that in Table 6, Table 7 and Table 8 a measure is provided of the potential value associated with all design flexibility options through the calculated ENPV differences between the "flexible" and the baseline case under various initial $\mathrm{CO}_{2}$ tax rates, tax growth rates and years of tax introduction. It is this value of optionality that underlies managerial decision-making as regulatory uncertainties become progressively resolved that cannot be captured through traditional valuation frameworks while it can be satisfactorily estimated through the proposed methodological and analytical framework. Finally, the effect of various model inputs on NPV-performance for the various design flexibility options is investigated and analyzed through Tornado diagrams. A Tornado diagram, as shown in Figure 10, graphically captures the relative impact of variations of the numerous uncertain model inputs over their specified ranges (lowest to highest value) while keeping all other model inputs fixed at their baseline values. All bars in the figure are sorted from the long ones at the top to the shorter ones at the bottom in a decreasing impact order, thus graphically illustrating the relative impact of uncertain model inputs on ENPV [23]. The uncertain model inputs considered and their respective prescribed ranges include the following: initial $\mathrm{CO}_{2}$ tax rate: $0-\$ 60$ per tonne of $\mathrm{CO}_{2}$, expected growth rate of $\mathrm{CO}_{2}$ tax: $0-10 \%$, volatility of $\mathrm{CO}_{2}$ tax: $0-20 \%$, financing interest to total capital investment ratio range: 6-10\%, capacity factor without CCS: 80-90\%, capacity factor with CCS: $75-85 \%$, de-rating factor without pre-investment: 5-10\%, de-rating factor with pre-investment: 0-5\%.

Figure 10 shows that the initial $\mathrm{CO}_{2}$ tax rate has the most significant impact on NPVperformance in Case A, Case B, Case E, and Case F, while the plant's capacity factor with CCS has the most significant impact on economic performance in Case $\mathrm{C}$ and Case D. This result suggests that the inclusion of a CCS system in the initial design phase can substantially mitigate the potential negative impact of a $\mathrm{CO}_{2}$ tax rate on the plant's economic performance by reducing $\mathrm{CO}_{2}$ emissions and thus preventing losses associated with the "carbon tax penalty" and assorted regulatory compliance costs. As a result, in such a case, it is the plant's capacity factor with CCS that appears as the factor with a significant impact on NPV-performance (since it is intimately related to hydrogen sales and the stream of revenue generated). The Tornado diagrams in cases associated with design flexibility options (particularly Case $\mathrm{C}$, Case $\mathrm{D}$, Case $\mathrm{E}$, and Case $\mathrm{F}$ ) display shorter bars for the initial $\mathrm{CO}_{2}$ tax rate and the expected tax growth rate on the left side of the baseline value. Indeed, these cases become less 
sensitive to higher initial $\mathrm{CO}_{2}$ tax rates and expected tax growth rates, since the inclusion of a CCS system can mitigate losses associated with the "carbon tax penalty" which increases as initial $\mathrm{CO}_{2} \operatorname{tax}$ rates and/or the expected growth rates of $\mathrm{CO}_{2}$ tax increase. When comparing the cases without and with design flexibility option in plant operation (Case A and Case B), Case B has shorter bars on the left side of the baseline value, even though the order of the relative impact of uncertain model inputs on NPV-performance in both cases is the same. This result implies that the operational flexibility option can indeed effectively alleviate downside risks in economic performance profiles.

Cases $\mathrm{C}$ and $\mathrm{D}$ are examined to investigate the value-enhancing properties of coupling operational and constructional flexibility options for CCS systems. As shown in Figure 10, Case D has longer bars for the initial $\mathrm{CO}_{2}$ tax rate and the expected $\mathrm{CO}_{2}$ tax growth rate on the right side of the baseline value, implying that the operational flexibility option for the CCS system can effectively enhance upside opportunities at lower values of the "carbon tax penalty." Therefore, Case D could produce higher ENPVs than Case $\mathrm{C}$ under lower initial $\mathrm{CO}_{2}$ tax rates and/or $\mathrm{CO}_{2}$ tax growth rates.

The effect of the pre-investment option on NPV-performance is studied by comparing Case E and Case F. Figure 10 shows that Case $\mathrm{E}$ has longer bars for the initial $\mathrm{CO}_{2}$ tax rate, the expected $\mathrm{CO}_{2}$ tax growth rate, the volatility of the $\mathrm{CO}_{2}$ tax, and the plant capacity factor without the CCS. This result may be attributed to the expected service time of the CCS system. In the present study, even though Case E and Case F have the same decision rules for retrofitting the plant with a CCS system (Table 1), Case F performs the retrofitting earlier than Case E due to the pre-investment option in a CCS-ready plant. As a result, the impact on NPV-performance is more pronounced in Case E (caused by the cash flows before retrofitting), which results in a higher sensitivity to the capacity factor without the CCS as well as all other uncertain model inputs associated with the "carbon tax penalty." Furthermore, Case F has a longer bar for the financing interest, indicating its significant impact on NPV-performance due to the higher TCI and capital expenditures associated with the pre-investment option. 


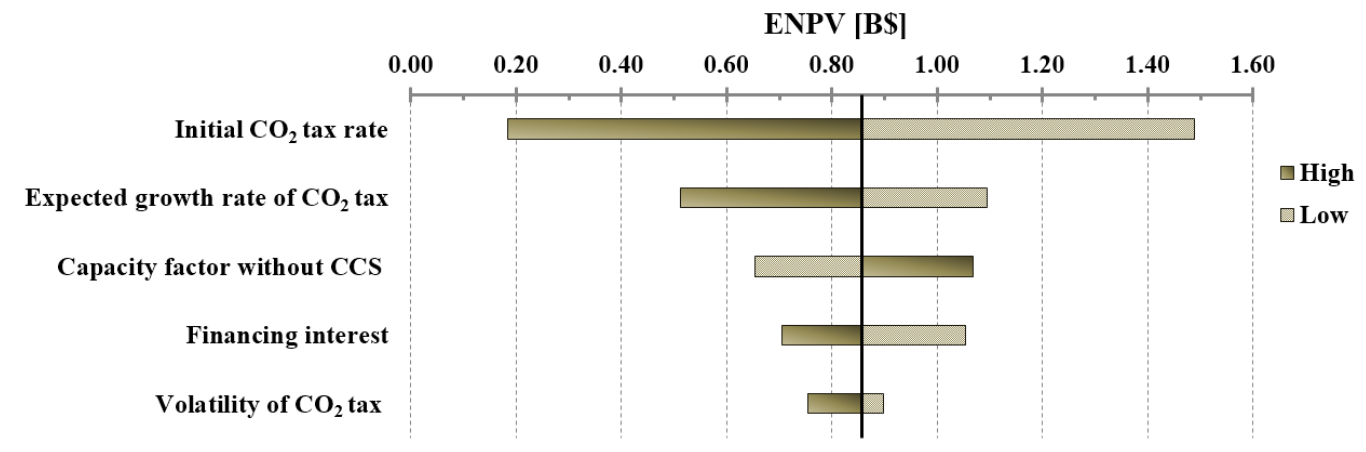

(a) Case A

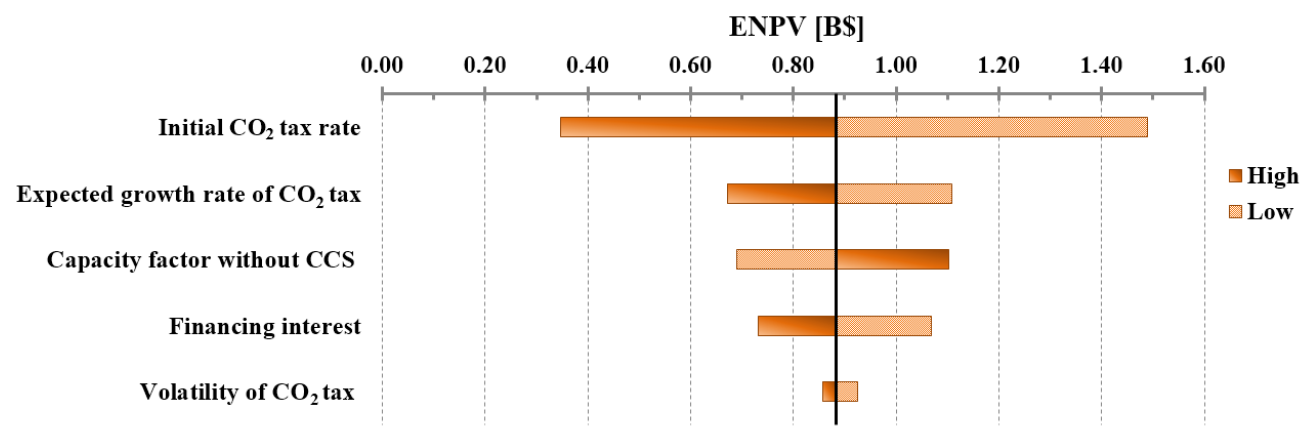

(b) Case B

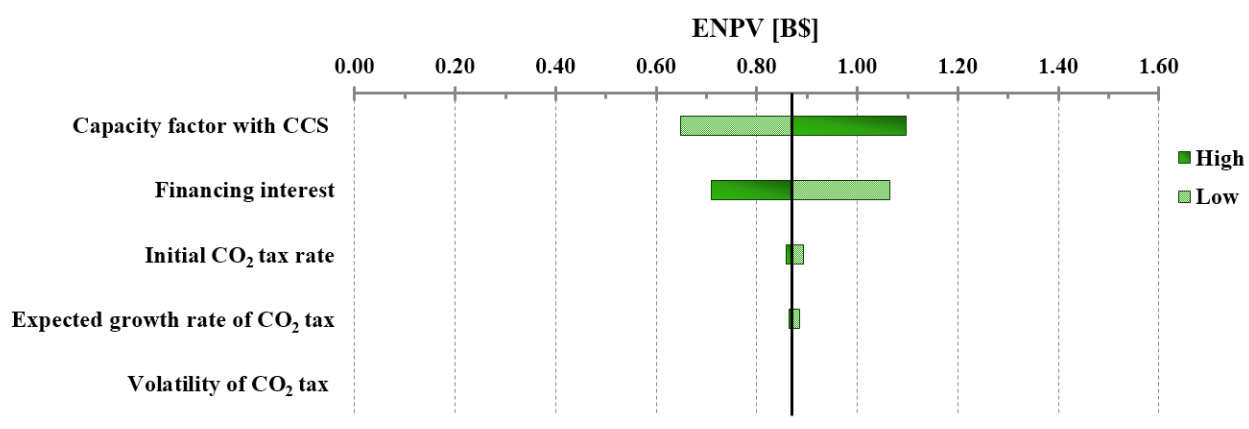

(c) Case C

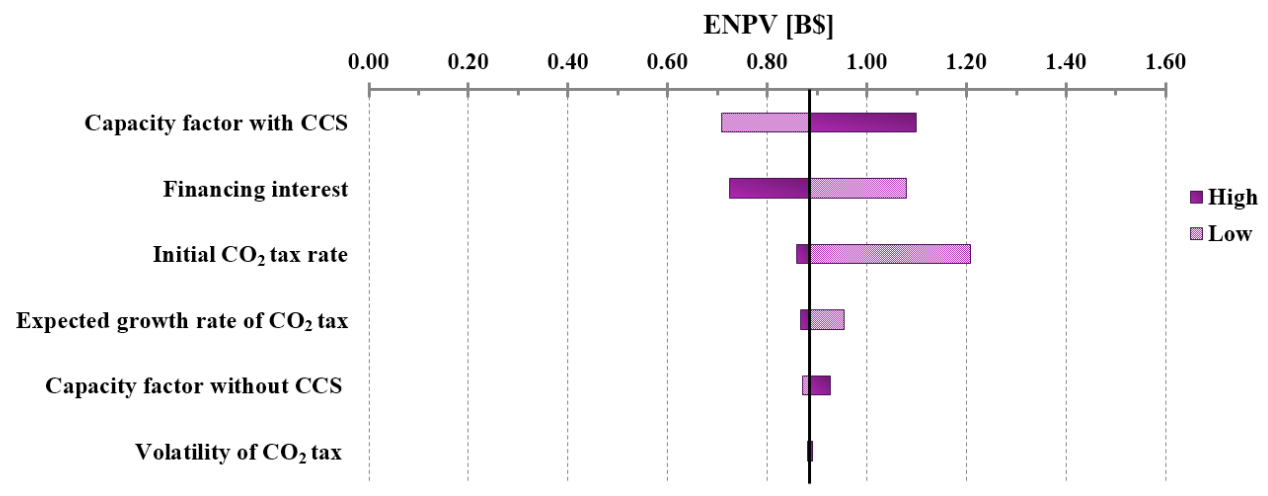

(d) Case D 


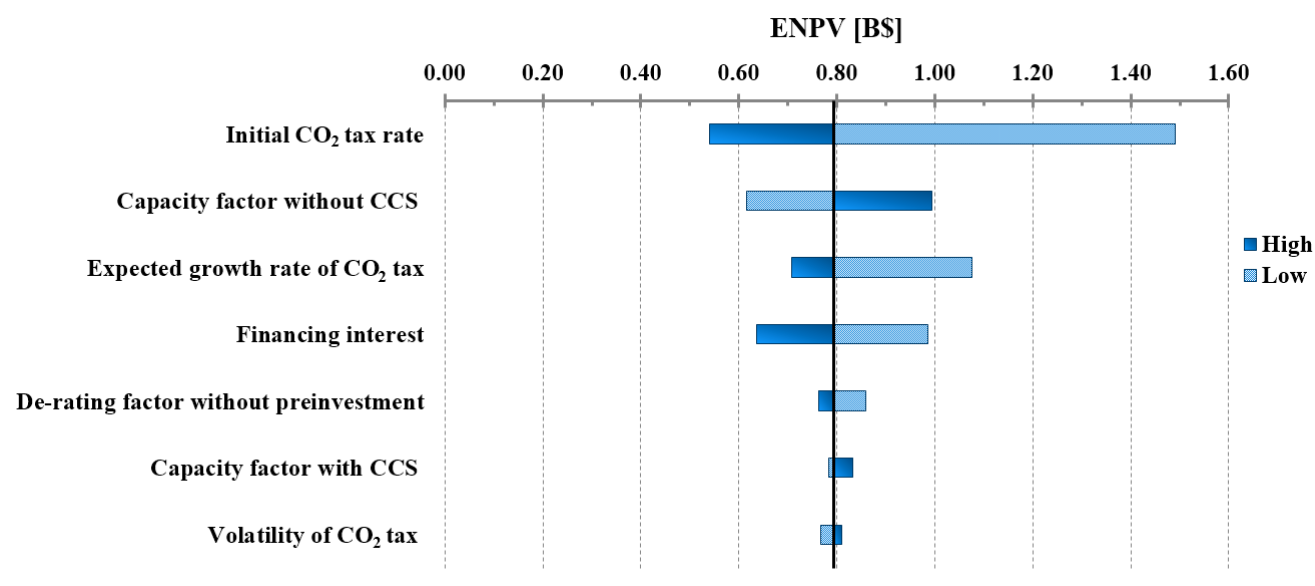

(e) Case E

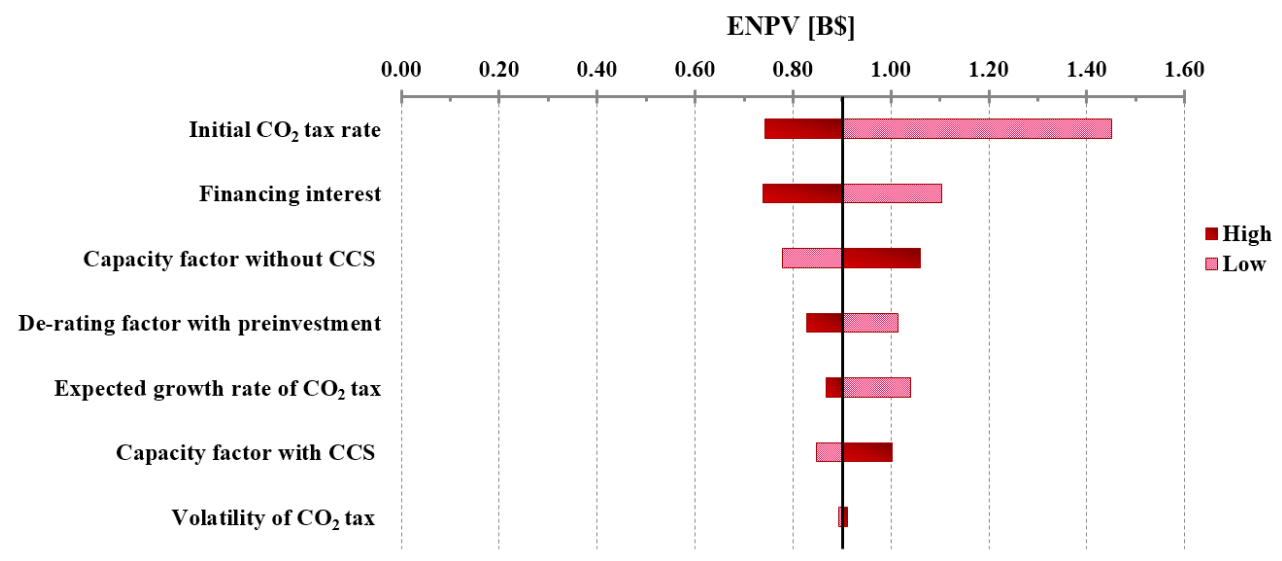

(f) Case F

\section{Figure 10. ENPV Tornado diagrams for the various design flexibility options.}

\section{Concluding Remarks}

Within the methodological framework developed in the present study, it was shown that the introduction and strategic use of various engineering design flexibility options can produce further economic gains over a plant's lifetime since they allow irreducible uncertainties to be explicitly acknowledged and better managed through an integration of the optionality element inherent in managerial flexibility (to respond to the above uncertainties as they get progressively resolved) into the proposed valuation framework. Indeed, engineers, managers and technology policy experts need to be aware of the fact that irreducible sources of uncertainty with asymmetric impact on the system's 
economic performance profile (an inherent characteristic of complex process systems) ought to be explicitly acknowledged and integrated into a comprehensive economic performance and valuation assessment framework through integrated Monte Carlo techniques. Therefore, one of the present study's primary objective is to develop a methodological framework for the economic evaluation of flexible design options that allows the identification of zones/ranges of potential economic risks and opportunities in the presence of uncertainty rather than generating single-point cost/value-estimates where uncertainty is conveniently ignored. Specifically, the present research work led to the development of a systematic Net Present Value (NPV)-based valuation framework with integrated Monte Carlo simulation capabilities within which potentially value-enhancing flexibility options for plants can be evaluated under various irreducible uncertainties. In particular, the proposed approach was applied and evaluated in a new technology option namely a hydrogen production plant operating with embedded catalytic membrane reactors (HP-CMR) that could potentially display quite promising environmental as well as appealing economic performance characteristics under certain market and regulatory conditions. Table 9 and Table 10 provide a quantitative as well as a qualitative summary of the analysis main outcomes and the study's key findings/conclusions for all cases where various design flexibility options were introduced. In light of the above tabulated findings, one arrives at the main conclusion than under certain scenarios of future regulatory action on $\mathrm{CO}_{2}$ emissions, quite appealing economic performance outcomes could emerge for HP-CMR plants once design flexibility is introduced and optionality in managerial decision-making is explicitly acknowledged and appropriately exercised. Furthermore, the results of this work demonstrate the value-enhancing capacity of design flexibility options for process scale up/development involving new technologies. Finally, in light of the above realizations, the proposed approach could further support the assessment of the viability prospects of new technology options in a carbon-constrained world and potentially inform policy initiatives aiming at unlocking investments in technology demonstration projects at the commercial scale. In this manner, valuable technical data can be generated as well as useful operating experience that could eventually reduce technology risks while enhancing the reliability of economic performance evaluation methods. 
Table 9. Quantitative summary of HP-CMR economic performance outcomes for all cases.

\begin{tabular}{lllllll}
\hline & \multicolumn{7}{l}{ In the presence of $\mathrm{CO}_{2}$ tax } \\
\cline { 2 - 7 } & Case A & Case B & Case C & Case D & Case E & Case F \\
\hline Maximum value [B \$] & 3.36 & 3.65 & 3.38 & 3.44 & 3.52 & 3.65 \\
Minimum value [B \$] & -3.33 & -1.73 & -2.29 & -2.26 & -2.23 & -2.14 \\
$\mathrm{P}_{95}[\mathrm{~B} \$]$ & 2.26 & 2.27 & 2.19 & 2.21 & 2.18 & 2.25 \\
$\mathrm{ENPV}[\mathrm{B} \$]$ & 0.86 & 0.88 & 0.87 & 0.88 & 0.79 & 0.90 \\
$\mathrm{P}_{5}[\mathrm{~B} \$]$ & -0.91 & -0.83 & -0.76 & -0.76 & -0.90 & -0.77 \\
Standard deviation [B $\$]$ & 1.01 & 0.98 & 0.93 & 0.93 & 0.97 & 0.96 \\
Spread [B \$] & 3.17 & 3.11 & 2.94 & 2.97 & 3.08 & 3.02 \\
Probability of loss & $23 \%$ & $22 \%$ & $22 \%$ & $22 \%$ & $24 \%$ & $21 \%$ \\
$\begin{array}{l}\text { Initial ETCI (CAPEX } \\
\text { measure) [B } \$ \text { ] }\end{array}$ & 1.52 & 1.52 & 1.57 & 1.57 & 1.52 & 1.55 \\
$\begin{array}{l}\text { Expected service time of } \\
\text { the CCS system [year] }\end{array}$ & N/A & N/A & 30.00 & 30.0 & 12.9 & 19.8 \\
\hline
\end{tabular}


Table 10. Qualitative summary of the analysis outcomes.

\begin{tabular}{|c|c|}
\hline Case Notation & Quantitative summary of performance \\
\hline Case A & - The lowest initial CAPEX \\
\hline Case B & $\begin{array}{l}\text { - The highest NPV under the most favorable scenario } \\
\text { - The highest NPV under the worst case scenario } \\
\text { - The highest Value at Opportunity } \\
\text { - The lowest initial CAPEX } \\
\text { - The lowest sensitivity to financing interest }\end{array}$ \\
\hline Case C & $\begin{array}{l}\text { - The highest Value at Risk } \\
\text { - The smallest standard deviation } \\
\text { - The smallest spread } \\
\text { - The lowest sensitivity to initial } \mathrm{CO}_{2} \text { tax rate } \\
\text { - The lowest sensitivity to the expected growth rate of } \mathrm{CO}_{2} \\
\text { tax } \\
\text { - The lowest sensitivity to the volatility of } \mathrm{CO}_{2} \text { tax }\end{array}$ \\
\hline Case D & $\begin{array}{l}\text { - The highest Value at Risk } \\
\text { - The smallest standard deviation } \\
\text { - The lowest sensitivity to the capacity factor without CCS }\end{array}$ \\
\hline Case E & $\begin{array}{l}\text { - The lowest initial CAPEX } \\
\text { - The lowest sensitivity to the capacity factor with CCS } \\
\text { - The lowest sensitivity to the de-rating factor }\end{array}$ \\
\hline Case F & $\begin{array}{l}\text { - The highest NPV under the most favorable scenario } \\
\text { - The highest ENPV } \\
\text { - The lowest probability of loss }\end{array}$ \\
\hline
\end{tabular}




\section{Nomenclature}

\begin{tabular}{|c|c|c|}
\hline Abbreviation/Symbol & Description & Unit \\
\hline CCS & carbon capture and sequestration & N/A \\
\hline CMRs & catalytic membrane reactors & N/A \\
\hline HP & $\mathrm{H}_{2}$ production & N/A \\
\hline WGS & water gas shift & N/A \\
\hline HTS & high temperature shift & N/A \\
\hline IGCC & integrated gasification combined cycle & N/A \\
\hline DCF & discounted cash flow & $\mathrm{B} \$$ \\
\hline NPV & net present value & B\$ \\
\hline ENPV & expected net present value & $\mathrm{B} \$$ \\
\hline FCI & fixed capital investment & $\mathrm{B} \$$ \\
\hline TCI & total capital investment & $\mathrm{B} \$$ \\
\hline ETCI & expected total capital investment & B\$ \\
\hline $\mathrm{WC}$ & working capital & $\mathrm{B} \$$ \\
\hline TPC & total product cost & $\mathrm{B} \$$ \\
\hline $\mathrm{CF}_{\mathrm{t}}$ & nominal net cash flow in year $\mathrm{t}$ & $\mathrm{B} \$$ \\
\hline $\mathrm{PC}$ & production cost & B\$ \\
\hline GE & general expenses & $\mathrm{B} \$$ \\
\hline $\mathrm{OC}$ & operating costs & $\mathrm{B} \$$ \\
\hline $\mathrm{O} \& \mathrm{M}$ & operation and maintenance & N/A \\
\hline CTSC & $\mathrm{CO}_{2}$ transport and storage costs & $\mathrm{B} \$$ \\
\hline HDC & $\mathrm{H}_{2}$ delivery cost & $\mathrm{B} \$$ \\
\hline CT & carbon tax & $\mathrm{B} \$$ \\
\hline INS & insurance & $\mathrm{B} \$$ \\
\hline PR & patents and royalties & B\$ \\
\hline POC & plant overhead costs & $\mathrm{B} \$$ \\
\hline $\mathrm{AC}$ & administrative costs & $\mathrm{B} \$$ \\
\hline $\mathrm{MC}$ & marketing costs & $\mathrm{B} \$$ \\
\hline R\&D & research and development & N/A \\
\hline RDC & research and development cost & $\mathrm{B} \$$ \\
\hline FIC & financing interest costs & $\mathrm{B} \$$ \\
\hline $\mathrm{SP}_{\mathrm{t}}$ & selling price of $\mathrm{H}_{2}$ at year $\mathrm{t}$ & $\$ / \mathrm{kg}$ \\
\hline $\mathrm{CPF}_{\mathrm{t}}$ & capacity factor at year $\mathrm{t}$ & $\%$ \\
\hline PS & plant production capacity & tonne/day \\
\hline $\mathrm{DF}_{\mathrm{t}}$ & de-rating factor at year $\mathrm{t}$ & $\%$ \\
\hline $\mathrm{CPI}_{t}$ & consumer price index at year $\mathrm{t}$ & $\%$ \\
\hline $\mathrm{DR}_{\mathrm{t}}$ & depreciation rate in year $t$ & $\%$ \\
\hline SV & salvage value & $\mathrm{B} \$$ \\
\hline $\mathrm{MV}$ & market value & $\mathrm{B} \$$ \\
\hline $\mathrm{BV}$ & book value & $\mathrm{B} \$$ \\
\hline
\end{tabular}




\begin{tabular}{|l|l|l|}
\hline ND & normal distribution & N/A \\
\hline SUD & simple uniform distribution & N/A \\
\hline TD & triangular distribution & N/A \\
\hline BD & bootstrap distribution & N/A \\
\hline CAPEX & Capital expenditure & B \$ \\
\hline$r$ & nominal discount rate & $\%$ \\
\hline$R_{t}$ & annual revenue generated by $\mathrm{H}_{2}$ sales at year $\mathrm{t}$ & $\mathrm{B} \$$ \\
\hline$\alpha_{\mathrm{t}}$ & inflation rate at year t & $\%$ \\
\hline$\psi_{\mathrm{t}}$ & tax shield generated by depreciation in year $t$ & $\mathrm{~B} \$$ \\
\hline$\theta_{\text {Federal }}$ & federal corporate tax rate & $\%$ \\
\hline$\theta_{\text {State }}$ & combined state and local sales tax rate & $\%$ \\
\hline$\mu$ & expected growth rate of $\mathrm{CO}_{2}$ tax & $\%$ \\
\hline$\sigma$ & volatility of $\mathrm{CO}_{2}$ tax rate & $\%$ \\
\hline
\end{tabular}

\section{Acknowledgment}

The authors are grateful to the anonymous reviewers as well as Professor. E. Pistikopoulos for their valuable suggestions and thoughtful remarks. The authors also gratefully acknowledge the financial support provided by the U.S. Department of Energy through Grant No. DE-FE0004895.

\section{References}

[1] C.-J. Winter, Hydrogen Energy - Abundant, Efficient, Clean: A Debate over the Energy-Systemof-Change, Int. J. Hydrogen Energy 34 (2009) S1-S52.

[2] A. Midilli, M. Ay, I. Dincer, M.A. Rosen, On Hydrogen and Hydrogen Energy Strategies: I: Current Status and Needs, Renew. Sustain. Energy Rev. 9 (2005) 255-271.

[3] U.S. Energy Information Administration (U.S. EIA), International Energy Statistics, 2015. Available from: http://www.eia.gov/cfapps/ipdbproject/IEDIndex3.cfm?tid=1\&pid=7\&aid=6 (accessed 11.09.15).

[4] International Energy Agency (IEA), $\mathrm{CO}_{2}$ emission from fuel combustion highlights 2014, 2014. Available from:

https://www.iea.org/publications/freepublications/publication/CO2EmissionsFromFuelCombustionHig hlights2014.pdf (accessed 11.09.2015).

[5] F. Mueller-Langer, E. Tzimas, M. Kaltschmitt, S. Peteves, Techno-economic Assessment of Hydrogen Production Processes for the Hydrogen Economy for the Short and Medium Term, Int. J. Hydrogen Energy 32 (2007) 3797-3810.

[6] R. Kothari, D. Buddhi, R.L. Sawhney, Comparison of Environmental and Economic Aspects of Various Hydrogen Production Methods, Renew. Sustain. Energy Rev. 12 (2008) 553-563. 
[7] V.H. Chou, N.J. Kuehn, Assessment of Hydrogen Production with $\mathrm{CO}_{2}$ Capture. Vol. 1: Baseline State-of-the-Art Plants. DOE/NETL, 2010. Available from:

http://www.canadiancleanpowercoalition.com/pdf/SMR9\%20-\%20H2_Prod_Vol1_2010.pdf (accessed 11.09.2014).

[8] M.M. El-Halwagi, Sustainable Design Through Process Integration: Fundamentals and Applications to Industrial Pollution Prevention, Resource Conservation, and Profitability Enhancement, Butterworth-Heinemann, Oxford, UK, 2012.

[9] L.-C. Ma, B. Castro-Dominguez, N.K. Kazantzis, Y.H. Ma, Integration of Membrane Technology into Hydrogen Production Plants with $\mathrm{CO}_{2}$ Capture: An Economic Performance Assessment Study, Int. J. Greenh. Gas Control 42 (2015) 424-438.

[10] M. Kanniche, R. Gros-Bonnivard, P. Jaud, J. Valle-Marcos, J.M. Amann, C. Bouallou, PreCombustion, Post-Combustion and Oxy-Combustion in Thermal Power Plant for $\mathrm{CO}_{2}$ Capture, Appl. Therm. Eng. 30 (2010) 53-62.

[11] X. Dong, Y.S. Lin, Catalyst-Free Ceramic-Carbonate Dual Phase Membrane Reactor for Hydrogen Production from Gasifier Syngas, J. Membr. Sci. 520 (2016) 907-913.

[12] T.C. Merkel, M. Zhou, R.W. Baker, Carbon Dioxide Capture with Membranes at An IGCC Power Plant, J. Membr. Sci. 389 (2012) 441-450.

[13] H. Lin, Z. He, Z. Sun, J. Vu, A. Ng, M. Mohammed, J. Kniep, T.C. Merkel, T. Wu, R.C. Lambrecht, $\mathrm{CO}_{2}$-Selective Membranes for Hydrogen Production and $\mathrm{CO}_{2}$ Capture - Part I: Membrane Development, J. Membr. Sci. 457 (2014) 149-161.

[14] H. Lin, Z. He, Z. Sun, J. Kniep, A. Ng, R.W. Baker, T.C. Merkel, $\mathrm{CO}_{2}$-Selective Membranes for Hydrogen Production and $\mathrm{CO}_{2}$ Capture - Part II: Techno-Economic Analysis, J. Membr. Sci. 493 (2015) 794-806.

[15] F. Gallucci, E. Fernandez, P. Corengia, M. van Sint Annaland, Recent Advances on Membranes and Membrane Reactors for Hydrogen Production, Chem. Eng. Sci. 92 (2013) 40-66.

[16] A. Brunetti, A. Caravella, E. Fernandez, D.A. Pacheco Tanaka, F. Gallucci, E. Drioli, E. Curcio, J.L. Viviente, G. Barbieri, Syngas Upgrading in A Membrane Reactor with Thin Pd-Alloy Supported Membrane, Int. J. Hydrogen Energy 40 (2015) 10883-10893.

[17] M.D. Dolan, R. Donelson, N.C. Dave, Performance and Economics of a Pd-based Planar WGS Membrane Reactor for Coal Gasification, Int. J. Hydrogen Energy 35 (2010) 10994-11003.

[18] C.A. Scholes, K.H. Smith, S.E. Kentish, $\mathrm{CO}_{2}$ Capture from Pre-combustion Processes-Strategies for Membrane Gas Separation, Int. J. Greenh. Gas Control 4 (2010) 739-755.

[19] R. Koc, N.K. Kazantzis, Y.H. Ma, Process Safety Aspects in Water-Gas-Shift (WGS) Membrane Reactors used for Pure Hydrogen Production, J. Loss Prev. Process Ind. 24 (2011) 852-869.

[20] R. Koc, N.K. Kazantzis, Y.H. Ma, Membrane Technology embedded into IGCC Plants with $\mathrm{CO}_{2}$ Capture: An Economic Performance Evaluation under Uncertainty. Int. J. Greenh. Gas Control 26 (2014) 22-38.

[21] R. de Neufville, O.L. de Weck, D.D. Frey, D. Hastings, R. Larson, D. Simchi-Levi, K. Oye, A. Weigel, R. Welsch, Uncertainty Management for Engineering Systems Planning and Design, Engineering Systems Symposium, MIT, Cambridge, MA, 2004. 
[22] R. de Neufville, Real Options: Dealing with Uncertainty in Systems Planning and Design, Integr. Assess. 4 (2003) 26-34.

[23] R. de Neufville, S. Scholtes, Flexibility in Engineering Design, MIT Press, Cambridge, MA, 2011.

[24] M.A. Cardin, G.L. Kolfschoten, D.D. Frey, R. de Neufville, O.L. de Weck, D.M. Geltner, Empirical Evaluation of Procedures to Generate Flexibility in Engineering Systems and Improve Lifecycle Performance, Res. Eng. Design 24 (2013) 277-295.

[25] Banking Environment Initiative (BEI), An Options Approach to Unlocking Investment in Clean Energy, University of Cambridge, UK, 2012. Available from:

http://www.cisl.cam.ac.uk/publications/sustainable-finance-publications/bei-options-approachunlocking-investment-clean-energy (accessed 31.01.2015).

[26] J.H. Saleh, G. Mark, N.C. Jordan, Flexibility: A Multi-Disciplinary Literature Review and a Research Agenda for Designing Flexible Engineering Systems, J. Eng. Design 20 (2009) 307-323.

[27] E.M. Al-Mutairi, M.M. El-Halwagi, Environmental-Impact Reduction through Simultaneous Design, Scheduling, and Operation, Clean Techn. Environ. Policy 12 (2010) 537-545.

[28] J. Zhang, M.A. Cardin, N.K. Kazantzis, S.K.K. Ng, Y.H. Ma, Economic Evaluation of Flexibility in the Design of IGCC Plants with Integrated Membrane Reactor Modules, Systems Engineering 18 (2015) 208-227.

[29] L.-C. Ma, N.K. Kazantzis, Y.H. Ma, Natural gas in hydrogen production: a cost study, ICE Energy 168 (2015) 61-73.

[30] S. Benninga, Principles of Finance with Excel, Oxford University Press, NewYork \& Oxford, 2011.

[31] M. Peters, K. Timmerhaus, R. West, Plant Design and Economics for Chemical Engineers, McGraw-Hill Education, New York, 2003.

[32] L.-C. Ma, B. Castro-Dominguez, N.K. Kazantzis, Y.H. Ma, A Cost Assessment Study for A Large-Scale Water Gas Shift Catalytic Membrane Reactor Module in The Presence of Uncertainty, Sep. Purif. Techn. 166 (2016) 205-212.

[33] J.L. Haslbeck, N.J. Kuehn, E.G. Lewis, Cost and Performance Baseline for Fossil Energy Plants. Vol. 1: Bituminous Coal and Natural Gas to Electricity, DOE/NETL, 2013. Available from: http://www.netl.doe.gov/File\%20Library/Research/Energy\%20Analysis/OE/BitBase_FinRep_Rev2a3_20130919_1.pdf (accessed 11.09.14).

[34] Chemical Engineering Plant Cost Indexes.

Available from: http://www.chemengonline.com/pci (accessed 31.01.16).

[35] U.S. Department of Labor (U.S. DOL), CPI Detailed Report Data for February 2014. Available from: www.bls.gov/cpi/cpid1402.pdf (accessed 11.09.15).

[36] Internal Revenue Service (IRS), How to Depreciate Property, U.S. Department of the Treasury. Available from: https://www.irs.gov/publications/p946/ (accessed 11.09.15).

[37] Internal Revenue Service (IRS), 2014 Instructions for Form 1120S, U.S. Department of the Treasury, 2014. Available from: https://www.irs.gov/pub/irs-pdf/i1120s.pdf (accessed 11.09.15). 
[38] Tax Foundation, State and Local Sales Tax Rates in 2015. Available from:

http://taxfoundation.org/article/state-and-local-sales-tax-rates-2015 (accessed 11.09.15).

[39] I. Karatzas, S.E. Shreve, Brownian Motion and Stochastic Calculus, 2th edition, Springer, New York, 1998.

[40] L. S. Savage, Decision Making with Insight, Brooks/Cole, Belmont, CA, 2003.

[41] R.A. Brealey, S.C. Myers, F. Allen, Principles of Corporate Finance, 9th edition, McGraw-Hill, New York, 2008.

[42] K.W. Chau, The Validity of the Triangular Distribution Assumption in Monte Carlo Simulation of Construction Costs: Empirical Evidence from Hong Kong, Constr. manage. econ. 13 (1995) 15-21.

[43] F.O. Hoffman, J.S. Hammond, Propagation of Uncertainty in Risk Assessments: the Need to Distinguish between Uncertainty due to Lack of Knowledge and Uncertainty due to Variability, Risk Anal. 14 (1994) 707-712.

[44] B.R. Barmish, C.M. Lagoa, The Uniform Distribution: A Rigorous Justification for Its Use in Robustness Analysis, Math. Control Signals Syst. 10 (1997) 203-222.

[45] L. Kuipers, H. Niederreiter, Uniform Distribution of Sequences, Dover Publications, Mineola, NY, 2012.

[46] P. Glasserman, Monte Carlo Methods in Financial Engineering, Springer, New York, 2003.

[47] J.L. Simon, Resampling: The New Statistics, 2nd edition, Resampling Stats, Arlington, VA, 1997.

[48] M. Al-Juaied, A. Whitmore, Realistic Costs of Carbon Capture, Energy Technology Innovation Policy, Kennedy School of Government, Harvard University, Cambridge, MA, 2009. Available from: http://e360.yale.edu/images/digest/2009-ccs-report-harvard.pdf (accessed 11.09.14). 